\title{
AIM2 and NLRP3 inflammasomes activate both apoptotic and pyroptotic death pathways via ASC
}

\author{
V Sagulenko ${ }^{1}$, SJ Thygesen ${ }^{1}$, DP Sester ${ }^{1}$, A Idris ${ }^{1}$, JA Cridland ${ }^{1}$, PR Vajjhala ${ }^{1}$, TL Roberts $^{2}$, K Schroder ${ }^{3}$, JE Vince ${ }^{4}$, \\ JM Hill ${ }^{1}$, J Silke ${ }^{4}$ and KJ Stacey ${ }^{*, 1,3}$
}

Inflammasomes are protein complexes assembled upon recognition of infection or cell damage signals, and serve as platforms for clustering and activation of procaspase-1. Oligomerisation of initiating proteins such as AIM2 (absent in melanoma-2) and NLRP3 (NOD-like receptor family, pyrin domain-containing-3) recruits procaspase-1 via the inflammasome adapter molecule ASC (apoptosis-associated speck-like protein containing a CARD). Active caspase-1 is responsible for rapid lytic cell death termed pyroptosis. Here we show that AIM2 and NLRP3 inflammasomes activate caspase-8 and -1, leading to both apoptotic and pyroptotic cell death. The AIM2 inflammasome is activated by cytosolic DNA. The balance between pyroptosis and apoptosis depended upon the amount of DNA, with apoptosis seen at lower transfected DNA concentrations. Pyroptosis had a higher threshold for activation, and dominated at high DNA concentrations because it happens more rapidly. Gene knockdown showed caspase-8 to be the apical caspase in the AIM2- and NLRP3-dependent apoptotic pathways, with little or no requirement for caspase-9. Procaspase-8 localised to ASC inflammasome 'specks' in cells, and bound directly to the pyrin domain of ASC. Thus caspase-8 is an integral part of the inflammasome, and this extends the relevance of the inflammasome to cell types that do not express caspase-1.

Cell Death and Differentiation (2013) 20, 1149-1160; doi:10.1038/cdd.2013.37; published online 3 May 2013

Inflammasomes are multiprotein complexes assembled in response to infection, cell damage or environmental stress, which lead to recruitment and activation of procaspase- $1 .{ }^{1}$ Caspase-1 cleaves prolL-1 $\beta$ and prolL-18 prior to their secretion as inflammatory cytokines, and also induces a rapid lytic cell death termed 'pyroptosis' that is morphologically different from apoptosis. ${ }^{2,3}$ Pyroptosis involves pore formation, osmotic swelling and early loss of membrane integrity, and is consequently inflammatory. ${ }^{4}$ This contrasts with apoptosis, the major form of cell death during development, which is considered immunologically silent as membrane integrity is maintained until cells are phagocytosed in vivo. ${ }^{5}$ Apoptotic death involves cell shrinkage, nuclear condensation and fragmentation, membrane blebbing and exposure of phosphatidylserine on the outer membrane leaflet as a phagocytic stimulus.

Caspases are the critical effector molecules of both apoptotic and pyroptotic cell death. The caspase family of cysteine proteases can be divided into inflammatory caspases, such as mouse caspase-1 and -11 (human caspase-1, -4 and -5 ), and those involved in the initiation of apoptotic cell death. ${ }^{6,7}$ The pro-apoptotic caspases include initiator caspases, caspase-2, -8 and -9 , which cleave executioner caspases, such as caspase- 3 and -7 . Caspase- 3 and -7 then cleave many cellular proteins, leading to apoptosis. Initiation of apoptosis occurs broadly via the extrinsic or intrinsic pathway. In the extrinsic pathway, ligation of cell-surface death receptors such as Fas and tumour necrosis factor receptor-1 (TNFR1) leads to the formation of the deathinducing signalling complex (DISC), resulting in recruitment of procaspase-8 via its death effector domains (DEDs). ${ }^{8}$ The induced proximity of procaspase- 8 facilitates its activation via dimerisation and intermolecular cleavage. The dimerisation of procaspases underlies the activation of all initiator caspases. ${ }^{9}$ The intrinsic pathway of apoptosis involves induction of mitochondrial outer membrane permeability (MOMP), leading to cytosolic release of cytochrome $c$ and formation of the multiprotein 'apoptosome' complex that serves as a platform for activation of caspase-9. ${ }^{8}$

DNA within the cytosol signals danger and leads to the formation of an inflammasome dependent on AIM2 (absent in melanoma-2), a member of the PYHIN protein family. ${ }^{10-14}$ AIM2 binds to double-stranded DNA (dsDNA) via its HIN domain. ${ }^{12}$ According to the current paradigm, oligomerisation

\footnotetext{
${ }^{1}$ School of Chemistry and Molecular Biosciences, The University of Queensland, Brisbane, QLD 4072, Australia; ${ }^{2}$ Queensland Institute of Medical Research, Herston, Brisbane, QLD 4006, Australia; ${ }^{3}$ Institute for Molecular Bioscience, The University of Queensland, Brisbane, QLD 4072, Australia and ${ }^{4}$ Walter and Eliza Hall Institute, Parkville, Melbourne, VIC 3052, Australia

*Corresponding author: KJ Stacey, School of Chemistry and Molecular Biosciences, The University of Queensland, Brisbane, QLD 4072, Australia. Tel: +61 733654640 ; Fax: +61 7 33654273; E-mail: katryn.stacey@uq.edu.au

Keywords: inflammasome; AIM2; NLRP3; apoptosis; caspase-8

Abbreviations: BMM, bone marrow-derived macrophage; iBMM, immortalised bone marrow-derived macrophage; CT DNA, calf thymus DNA; dsDNA, doublestranded DNA; WT, wild type; STS, staurosporine; PBS, phosphate-buffered saline; Z-VAD-FMK, carbobenzoxy-valyl-alanyl-aspartyl-[O-methyl]-fluoromethylketone; PI, propidium iodide; MOMP, mitochondrial outer membrane permeability; LPS, lipopolysaccharide; HRP, horseradish peroxidase; siRNA, small interfering RNA; CARD, caspase recruitment domain; DED, death effector domain; DD, death domain; Spf, specific pathogen-free; PFA, paraformaldehyde; Alx, Alexa Fluor dyes; DAPI, 4',6-diamidino-2-phenylindole; FCS, foetal calf serum; MTT, thiazolyl blue tetrazolium bromide

Received 24.9.12; revised 30.1.13; accepted 21.3.13; Edited by G Salvesen; published online 03.5.2013
} 
of AIM2 along the length of the DNA recruits the adapter protein ASC (apoptosis-associated speck-like protein containing a CARD), which in turn recruits procaspase-1. Complex formation requires homotypic interactions between death-fold superfamily members, the pyrin domain and the caspase recruitment domain (CARD). ${ }^{15}$ AIM2 recruits ASC via pyrin-pyrin domain interaction and $A S C$ interacts with caspase-1 via CARD-CARD interaction. Clustering of procaspase-1 molecules leads to their intermolecular cleavage and activation. ${ }^{1}$ The AIM2 inflammasome is activated in response to DNA viruses such as MCMV and vaccinia, ${ }^{16}$ and is critical in defence against the cytosolic bacterium Francisella. ${ }^{17-19}$ Another inflammasome complex is initiated by the NLRP3 protein (NOD-like receptor family, pyrin domain-containing-3) in response to diverse stimuli such as extracellular ATP, the bacterial pore-forming toxin nigericin, monosodium urate crystals, asbestos and cholesterol crystals. ${ }^{1,20}$ Like AIM2, NLRP3 has a pyrin domain, and recruits ASC and procaspase-1 to form the inflammasome.

Inflammasome-mediated pyroptotic cell death is characterised as caspase-1-dependent and independent of caspase-3. ${ }^{2}$ However, we observed parallel cleavage of caspase-1 and -3 while investigating the mechanism of DNA-dependent death. ${ }^{13} \mathrm{~A}$ recently published work showed AIM2-dependent apoptosis induced by infection of caspase1-knockout macrophages with Francisella. ${ }^{21}$ We confirm that the DNA inflammasome induces apoptosis, and extend this to show a DNA dose-dependent switch between apoptosis and pyroptosis in wild-type (WT) cells, and induction of caspase-8-dependent apoptosis via the NLRP3 inflammasome. Procaspase- 8 colocalises with ASC in inflammasomes and binds to ASC in vitro. This provides a novel death-signalling platform for caspase-8, which is otherwise predominantly known for its role in the extrinsic pathway of cell death, and broadens the scope of inflammasomedependent responses to include cell types that do not express caspase-1.

\section{Results}

Caspase-1-dependent and -independent death initiated via ASC. Cytosolic dsDNA-dependent death was originally described as pyroptotic. ${ }^{11}$ Since cytosolic DNA induced similar cleavage of caspase- 1 and -3 in macrophages, ${ }^{13}$ we investigated the nature of the induced cell death in more depth. Casp1 $1^{-/}$cells were protected from rapid DNAinduced cell death at $1 \mathrm{~h}$ (Figure 1a). Thereafter, the Casp $1^{-/}$cells also began to die and showed little difference from WT cells by $3 \mathrm{~h}$ post DNA electroporation. The Casp1 $1^{-/-}$ mice are also deficient in the neighbouring Casp11 gene, as they were made using mouse strain 129 embryonic stem (ES) cells that are naturally deficient in caspase-11.22 Caspase-11 was not required for early cell death since the degree and timing of death in Casp $11^{-/-}$cells was identical to those in WT cells (Figure $1 \mathrm{~b}$ ). $A s c^{-/-}$cells were protected from DNA-induced death for up to $6 \mathrm{~h}$ (Figure 1c). Thus cell death within $1 \mathrm{~h}$ of introduction of DNA is dependent on caspase-1 and ASC, consistent with pyroptosis. Thereafter, cells died in a manner independent of caspase-1 or -11 , but dependent on the inflammasome adaptor ASC.
Caspase-1-independent cell death is apoptotic. Pyroptosis involves rapid loss of cell membrane integrity, whereas in apoptosis there is prolonged maintenance of membrane integrity and exposure of phosphatidylserine on cell surface. We investigated the mode of cell death by staining with Annexin- $V$, which binds to phosphatidylserine, and propidium iodide (PI), a membrane-impermeable DNA stain. By $1 \mathrm{~h}$ post transfection with DNA, the majority of WT bone marrowderived macrophages (BMMs) had lost membrane integrity and become PI-positive (Figure 2a), consistent with pyroptosis. ${ }^{11}$ By contrast, Casp $1^{-1-}$ BMMs predominantly stained positive for Annexin-V in response to DNA, but still excluded $\mathrm{PI}$, consistent with apoptosis. Cells lacking ASC failed to initiate either death pathway (Figure 2a).

Another hallmark of apoptosis is cleavage of DNA. This can be measured by the appearance of cells with an amount of DNA less than that found in $G_{0} / G_{1}$ cells. Analysis of DNA content showed sub- $\mathrm{G}_{0} / \mathrm{G}_{1} \mathrm{DNA}$, consistent with apoptosis in the Casp1 ${ }^{-/-}$cells (Figure 2b). Together, the Annexin-V-PI staining and DNA content analysis confirm that WT cells predominantly underwent pyroptotic death, whereas in the Casp $1^{-1-}$ cells, death was apoptotic. Annexin-V staining of WT cells at $1 \mathrm{~h}$ suggested some initiation of apoptosis, but the lack of cells with sub- $G_{0} / G_{1}$ DNA at $6 \mathrm{~h}$ suggests that the apoptotic program may then have been cut short by pyroptosis.

A 20- $\mu \mathrm{g}$ dose of DNA was used as shown in Figure $2 \mathrm{a}$ to induce profound cell death. We observed that the time course of death of WT cells was slower with lower amounts of DNA. Consequently, we examined the balance between pyroptosis and apoptosis over a DNA dose response at $6 \mathrm{~h}$ after introduction of DNA (Figure 2c). In WT cells, apoptotic death predominated at low DNA doses. At high DNA concentrations, most cells became PI-positive. At this 6-h time point, this could indicate either pyroptosis or late apoptosis. However, in Figure $2 \mathrm{a}$, we have established that the highest concentrations of DNA induced lytic death by $1 \mathrm{~h}$ post electroporation. Thus we conclude that there was a threshold of cytosolic DNA required for pyroptotic death, below which death was predominantly apoptotic.

We previously showed that caspase-3 was cleaved within 5 min of electroporation with DNA. ${ }^{13}$ To assess the contribution of caspase-3 and other apoptotic caspases to the caspase-1-independent DNA-induced cell death, we pretreated Casp $^{-1-}$ cells with the broad-spectrum caspase inhibitor Z-VAD-FMK (carbobenzoxy-valyl-alanyl-aspartyl-[Omethyl]-fluoromethylketone) prior to electroporation with DNA. The inhibitor reduced caspase-1-independent cell death in four independent experiments (Figure 2d), and blocked caspase-3 cleavage (Figure 2e), consistent with apoptosis. Procaspase-8 also showed DNA-dependent cleavage, which was sensitive to Z-VAD-FMK (Figure 2e). Further evidence for apoptotic death was provided by the cleavage of the caspase-3 substrate PARP-1 in DNA-electroporated Casp1 ${ }^{-1-}$ $\mathrm{BMMs}$, and to a lesser extent in WT cells (Figure 3a).

A range of caspases are cleaved, independent of caspase-1. We initially found that active caspase-3 was not reliably observed in lysates of DNA-transfected WT cells unless they were kept at room temperature (RT) ${ }^{13}$ 

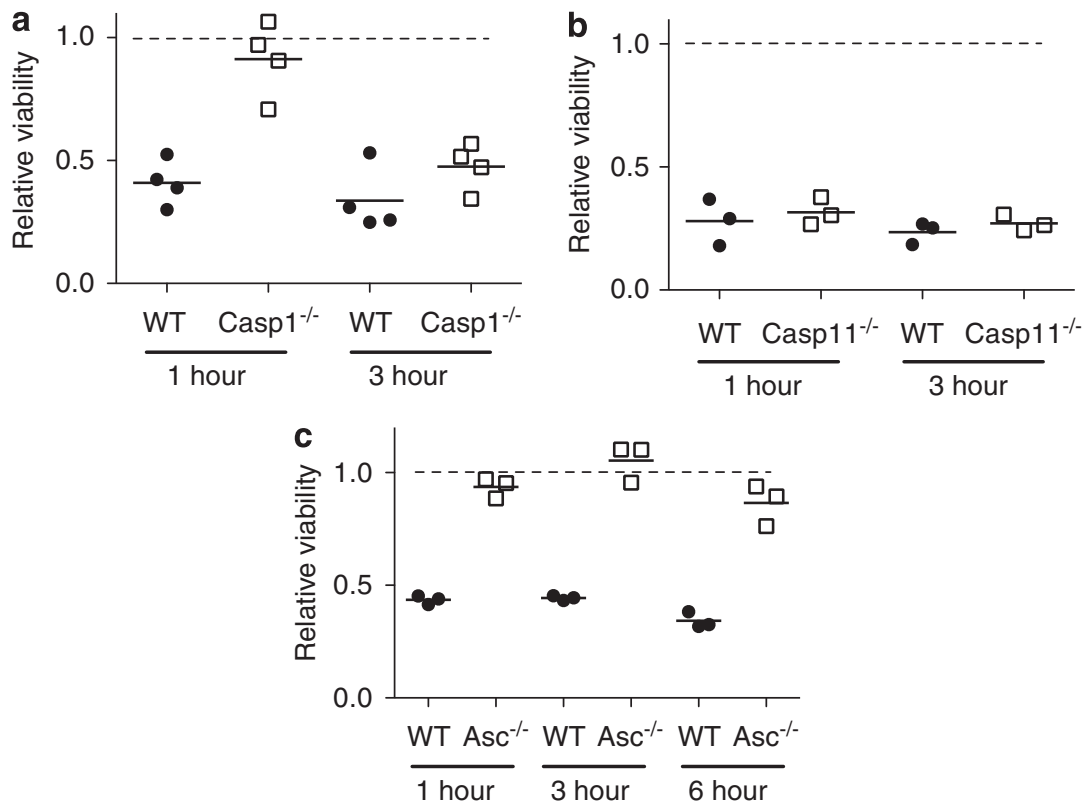

Figure 1 Cell death induced by cytosolic DNA in mouse macrophages is ASC-dependent, but has caspase-1-dependent and -independent phases. BMMs from WT and corresponding knockout mice were electroporated with $20 \mu \mathrm{g}$ of CT DNA. Cell viability was determined by MTT reduction, a measure of mitochondrial activity, at the indicated times post electroporation. Results from each time point were normalised to samples electroporated without DNA. The dotted line indicates no loss of viability relative to this control. Each data point shown is the result of an independent experiment and is the average of 2-3 separate electroporations within that experiment. (a) Viability of BMMs from Casp1 $1^{-/-}$and WT littermate mice in four independent experiments. (b) Viability of BMMs from Casp $11^{-/-}$and WT littermate mice in three independent experiments. (c) Viability of BMMs from $\mathrm{Asc}^{-/-}$and WT littermate mice in three independent experiments

(Supplementary Figure 1A). The key to the apparent temperature dependence was that DNA-transfected cells underwent pyroptotic lysis at $37^{\circ} \mathrm{C}$, releasing cleaved caspase-3 and -1 (Figure $3 \mathrm{a}$ and Supplementary Figure 1B). With incubation at $37^{\circ} \mathrm{C}$, cytosolic DNA also led to the release of the active forms of caspase- 8 and -7 , and an intermediate cleavage product of caspase-9, p39, into the medium (Figure 3a). Casp $1^{-1-}$ cells that underwent apoptosis but not pyroptosis, and thus did not lyse, retained the processed forms of apoptotic caspases-3, -7, -8 and -9 within them. Overall, these results confirmed that caspase- 1 was essential for rapid lytic pyroptosis, but was dispensable for induction of the apoptotic cascade. We next sought to establish whether cleavage of all these caspases was due to inflammasome activity.

ASC is essential for all caspase cleavage in response to cytosolic DNA. ASC is a crucial element of the AIM2 inflammasome and, in contrast to WT cells, processing of caspases-1, -3, -7 -8 or -9 was not induced by cytosolic DNA in $\mathrm{Asc}^{-1-}$ cells (Figure $3 \mathrm{~b}$ ). Thus cytosolic DNA induces the activation of the apoptotic cascade in an ASCdependent manner. The abundance of processed caspase-3 prompted us to identify the apical caspase responsible.

Caspase-3 cleavage is independent of caspase-2 and unaffected by $\mathrm{Bcl}-2$ overexpression. Caspase-3 and -7 are executioner caspases that are normally activated through cleavage by one of the initiator caspases, caspase8 , -9 , or $-2 .^{6}$ Caspase- 11 is dispensable for the caspase- 3

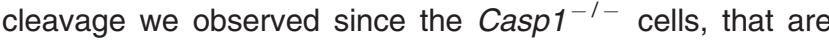

deficient in both caspase-1 and $-11,{ }^{22}$ showed strong caspase-3 cleavage upon DNA transfection (Figure 3a).

We attempted to identify the apical caspase by trapping with the inhibitor biotin-VAD-FMK. This method was not useful as inhibition of the apical caspase was not complete, allowing trapping of downstream caspases, as noted by others. ${ }^{23}$ We examined the requirement for caspase-2 in DNA-induced cleavage of caspase-3. We did not detect any active caspase-2 in the WT BMMs in response to DNA and caspase3 processing was undiminished in Casp2 $2^{-1-}$ BMMs transfected with calf thymus (CT) DNA or poly(dA):(dT) (Figure 4a). Thus in agreement with others, ${ }^{21}$ we found that caspase- 2 is not an apical caspase in response to cytosolic DNA.

In order to determine whether the mitochondrial intrinsic pathway of apoptosis was involved in caspase-3 processing, we examined the response to DNA in Bcl-2-overexpressing and WT BMMs. Bcl-2 inhibits the induction of MOMP, which precedes release of cytochrome $c$, apoptosome formation and activation of caspase- $9 .{ }^{5} \mathrm{Bcl}-2$ overexpression did not affect caspase-3 cleavage in response to DNA transfection (Figure 4b, upper panel). Staurosporine (STS) was used as a control to confirm the effect of Bcl-2 overexpression in these cells (Figure 4b, lower panel). ${ }^{24}$ We conclude that the intrinsic apoptotic pathway is not a dominant route for early caspase-3 cleavage in response to cytosolic DNA in WT macrophages. Caspase- 8 was a remaining candidate for the apical apoptotic caspase.

Caspase-8 is the apical caspase in DNA-induced apoptosis. To study the role of caspase-8, we used gene knockdown, since $\operatorname{Casp}^{-1-}$ mice suffer embryonic 
a

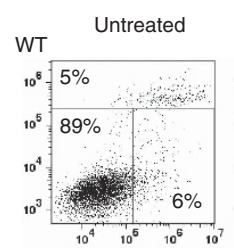

Casp1-/-

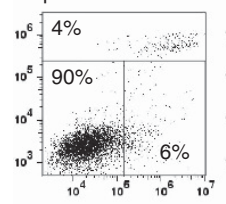

ASC--
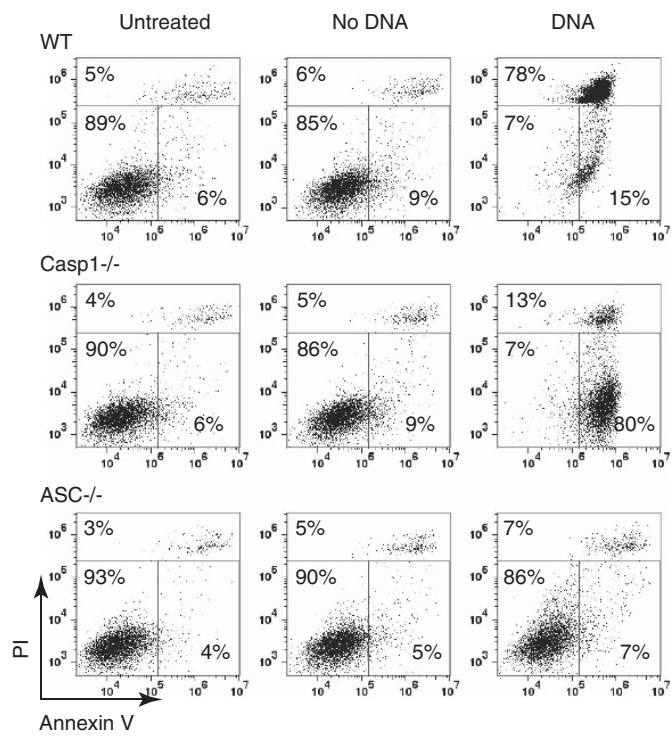

d
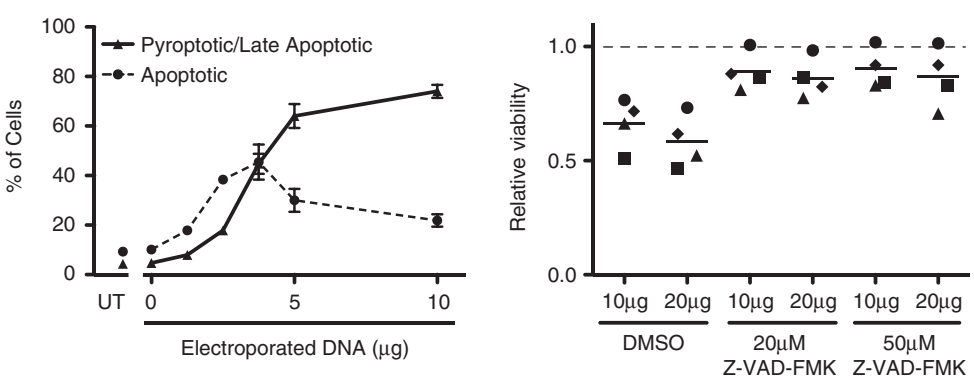

b

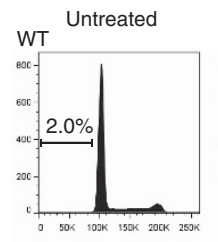

Casp1-/-

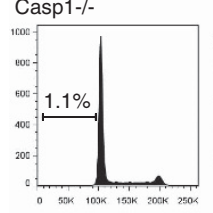

$$
\text { ASC-/- }
$$
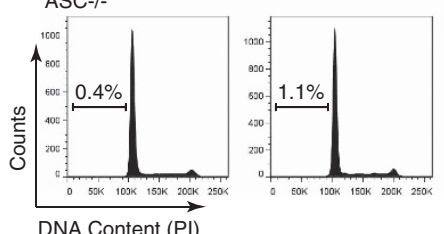
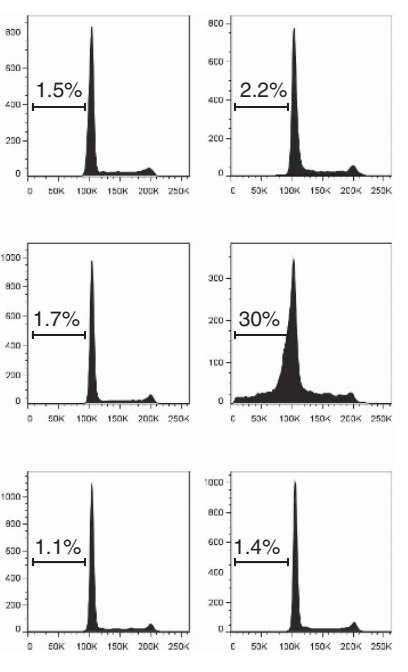
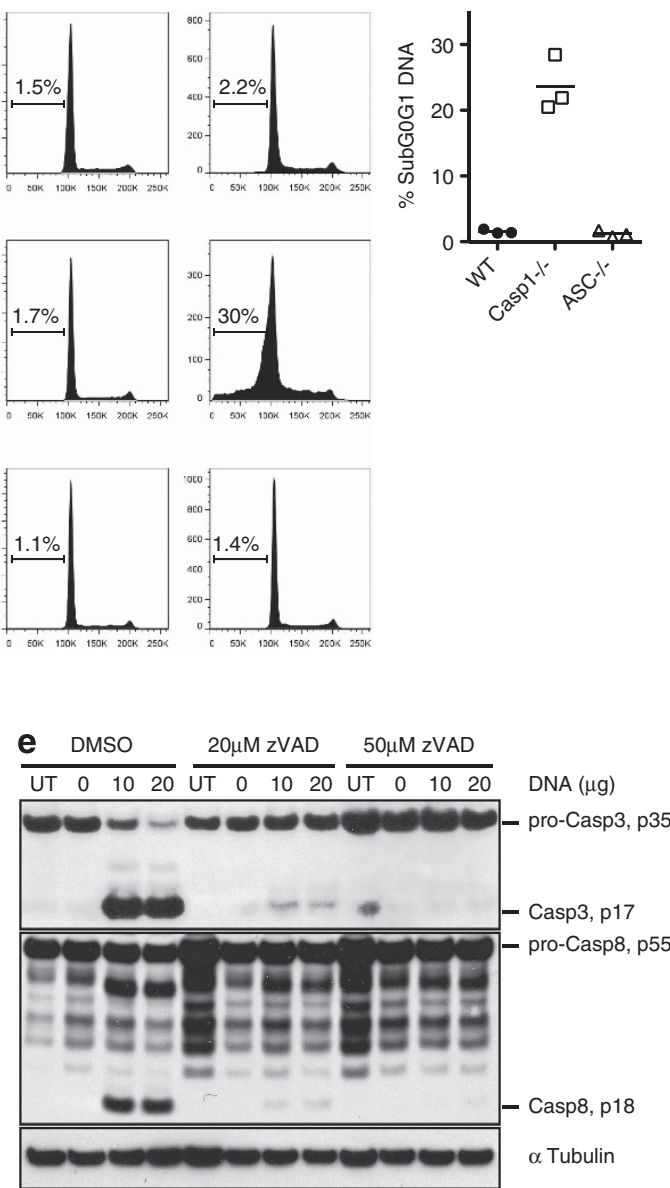

Figure 2 The DNA inflammasome activates both apoptosis and pyroptosis in a DNA dose-dependent manner. (a) Analysis of the cell death phenotype by Annexin-V-PI staining. BMMs from WT, Casp $1^{-1-}$ and $A s c^{-1-}$ mice were electroporated with or without $20 \mu \mathrm{g}$ of CT DNA. One hour post electroporation, cells were stained with Annexin$\mathrm{V}$ and $\mathrm{PI}$, and analysed by flow cytometry. Live cells are negative for both stains, whereas early apoptotic cells are characterised by a high Annexin-V signal in the absence of PI staining. Necrotic, pyroptotic and late-apoptotic cells have a high PI signal. The results shown are typical of four independent experiments. (b) Cells from the experiment shown in panel a were assessed for sub- $G_{0} / G_{1}$ DNA content by flow cytometry at $6 \mathrm{~h}$ post electroporation. Examples of primary data are shown, with a graph showing data from three independent experiments. (c) WT C57BL/6 BMMs die by apoptosis after electroporation with low DNA concentrations. BMMs were electroporated with the indicated amounts of DNA and analysed by Annexin-V-PI staining after $6 \mathrm{~h}$. The percentage of Annexin-V-positive/PI-negative cells was used to indicate apoptosis. The percentage of PI-positive cells was used to indicate pyroptotic and late-apoptotic cells. The results shown are the mean and range of duplicate electroporations. Apoptosis of WT cells with Iow DNA concentration was observed in four independent experiments. (d) The pan-caspase inhibitor Z-VAD-FMK prevents caspase-1-independent cell death. BMMs from Casp 1 $^{-1-}$ mice were pretreated for $1 \mathrm{~h}$ with 20 or $50 \mu \mathrm{M}$ Z-VAD-FMK, or a DMSO vehicle control, then electroporated with or without 10 or $20 \mu \mathrm{g}$ of CT DNA in the continued presence of Z-VAD-FMK. Cell viability was assayed by MTT reduction $3 \mathrm{~h}$ after electroporation. Results were normalised to samples electroporated without DNA, for each pretreatment regime. The dotted line indicates no loss of viability relative to this control. The results of four independent experiments are shown, with different symbols used for each experiment to show the consistent trend. (e) Cleavage of caspase-3 and -8 in response to cytosolic DNA in Casp1 ${ }^{-1-}$ BMMs was effectively inhibited by Z-VAD-FMK. Cells were treated in parallel with the experiment shown in panel $\mathbf{d}$, except they were lysed at $30 \mathrm{~min}$ post electroporation, and the levels of cleaved caspase-3 ( $\mathrm{p} 17$ ) and caspase-8 ( $\mathrm{p} 18)$ were analysed by western blot using $\alpha$-tubulin as a loading control

lethality ${ }^{25}$ and caspase- 8 is required for differentiation of macrophages. ${ }^{26}$ We knocked down caspase- 8 using three separate small interfering RNAs (siRNAs) in Casp1 ${ }^{-/-}$ immortalised BMMs (iBMMs) (Figure 4c). The knockdown profoundly inhibited the cleavage of both caspase-3 and -9 , implicating caspase- 8 as the apical protease in the pathway (Figure 4d). The caspase-8 blot in Figure $4 d$ is overexposed to show the cleaved caspase- 8 band, and the degree of knockdown for this experiment should be assessed from Figure 4c. Although a role for the intrinsic pathway of apoptosis was not supported by the lack of an effect of Bcl-2 overexpression on caspase-3 cleavage (Figure 4b), we further investigated any possible role of caspase-9. Knockdown of caspase-9 (Figure 4e) had little detectable effect on caspase-3 cleavage (Figure 4f). Although caspase-9 was cleaved in a caspase-8-dependent manner in response to DNA, we have no evidence that caspase- 9 was activated, and the exact molecular mechanism of the cleavage has not been established. Of note, in WT cells we detected the intermediate cleavage product of caspase-9 (p39), which has been attributed to direct cleavage by caspase- $3^{27}$ (Figure 3a). In the Casp1-1- cells, the smaller form of caspase-9 (p37) was prominent, which may result from autocatalytic cleavage due to apoptosome formation ${ }^{27}$ or 
a

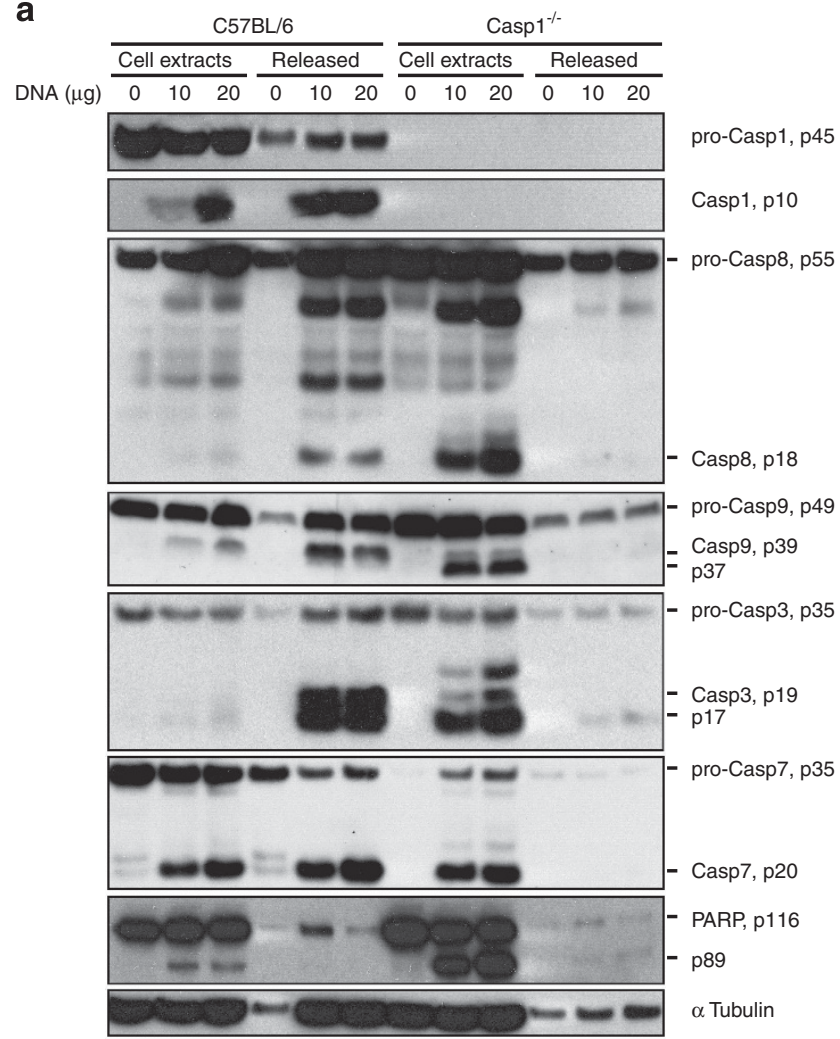

b

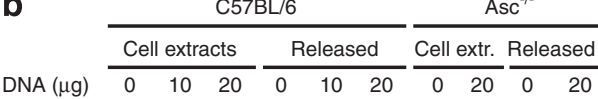

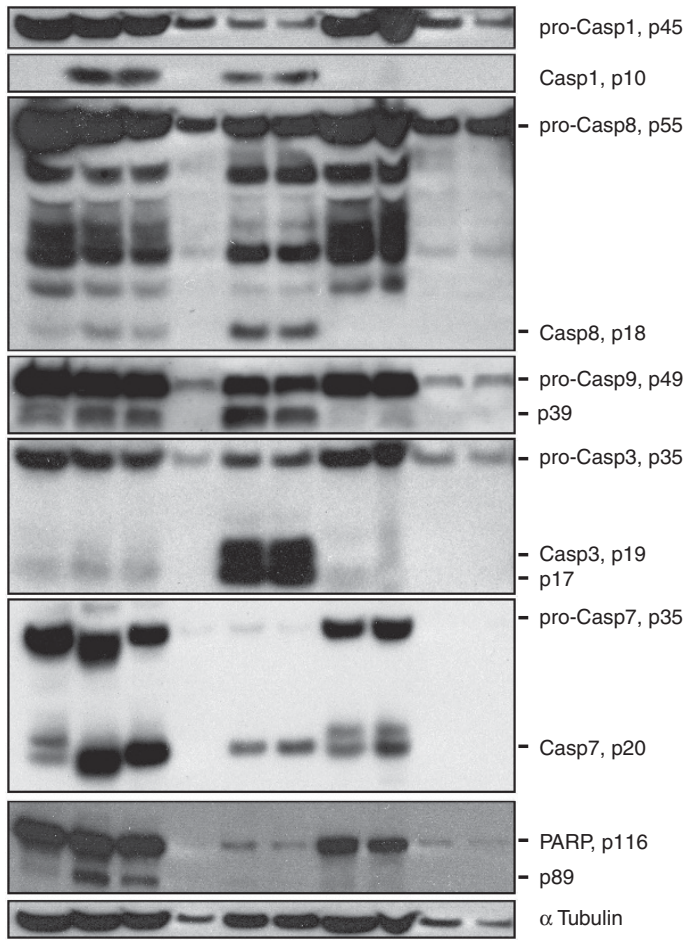

Figure 3 Cytosolic DNA activates apoptotic caspases independently of caspase-1 and -11, but depending on ASC. (a) Caspase-1 and -11 are dispensable for cleavage of

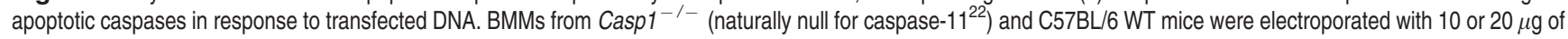
CT DNA. Cell lysates and proteins released into the culture medium were collected $30 \mathrm{~min}$ post electroporation, and analysed by western blot. (b) ASC is essential for activation of the apoptotic cascade in response to cytosolic DNA. BMMs from Asc ${ }^{-1-}$ and C57BL/6 WT mice were electroporated with 10 or $20 \mu \mathrm{g}$ of CT DNA. Cell lysates and proteins released into the tissue culture medium were collected $30 \mathrm{~min}$ post electroporation, and analysed by western blot

direct cleavage by caspase-8. ${ }^{28}$ This may occur more in Casp $1^{-1-}$ cells as they do not undergo pyroptosis, and hence have longer for caspase processing to occur.

To confirm that caspase-8-induced executioner caspase activation was primarily responsible for apoptotic death, we examined the effect of caspase- 8 and -9 knockdown on the apoptotic phenotype of the Casp $1^{-1-}$ cells, measured by Annexin- $V$ staining and sub- $G_{0} / G_{1}$ DNA (Figure $4 \mathrm{~g}$ ). The effectiveness of the knockdown in this experiment is shown in the bottom right panel. There was a correlation between the degree of caspase-8 knockdown and inhibition of apoptosis. In this experiment, caspase-8 siRNAs \#1 and \#2 effectively knocked down protein expression, and gave a pronounced reduction of both measures of apoptotic phenotype. Caspase-8 siRNA \#3 was less effective in knockdown and had correspondingly less effect on the number of apoptotic cells. Correlating with its minimal effect on caspase-3 cleavage (Figure 4f), caspase- 9 knockdown had only a minor effect on the number of apoptotic cells. Overall, these results confirm caspase- 8 as the apical caspase in AIM2 inflammasome-induced apoptosis, and show minimal, if any, role for caspase-9.

Minimal production of IL-1 $\beta$ in the absence of caspase-1. Although the most studied pathway leading to prolL-1 $\beta$ cleavage is via inflammasome activation of caspase-1, several studies have reported cleavage of prolL-
$1 \beta$ by caspase-8. ${ }^{29-32}$ Despite caspase-8 activation by cytosolic DNA, we found that production of active IL-1 $\beta$ was very low in the absence of caspase-1 (Supplementary Figure 2). In the Casp $1^{-1-}$ cells, there was a prominent cleavage of prolL- $1 \beta$ to a $28-\mathrm{kDa}$ form that is not active. ${ }^{33}$

The NLRP3 inflammasome activates apoptosis. Having provided evidence for ASC-dependent activation of procaspase-8 in the DNA inflammasome response, we asked whether similar effects are seen with the ASC-dependent NLRP3 inflammasome. The bacterial pore-forming toxin nigericin is a potent stimulus for NLRP3 and it led to dosedependent death of WT cells, predominantly within the first hour of treatment (Figure 5a). The Casp1 $1^{-1-}$ cells showed no death within the first hour, but died progressively starting at $2 \mathrm{~h}$, whereas $A s \mathrm{C}^{-/-}$and $N L R P 3^{-/-}$cells were protected from death for at least $6 \mathrm{~h}$. Staining cells with PI-Annexin-V as well as examination of DNA fragmentation by sub- $\mathrm{G}_{0} / \mathrm{G}_{1}$ DNA confirmed that the WT cell death was characteristically pyroptotic and the Casp1 $1^{-/-}$cell death was apoptotic (Figures $5 \mathrm{~b}$ and $\mathrm{c}$ ). Conventional NLRP3 inflammasome activation is dependent on priming with a toll-like receptor stimulus such as lipopolysaccharide (LPS), which induces NLRP3 and prolL-1 $\beta,{ }^{34}$ and has other uncharacterised roles in 'licensing' NLRP3 responses. ${ }^{35}$ The NLRP3-dependent apoptotic response in $\mathrm{Casp1}^{-/-}$cells is similarly dependent 
a

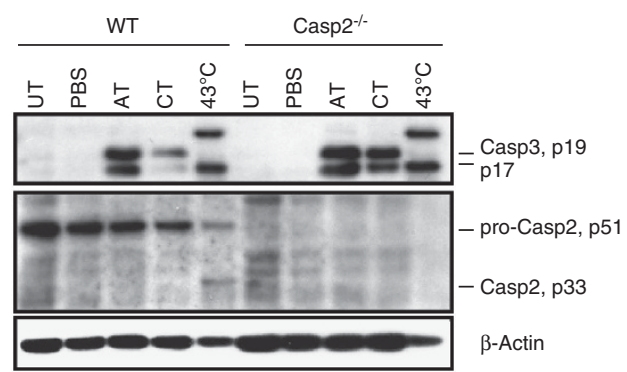

b

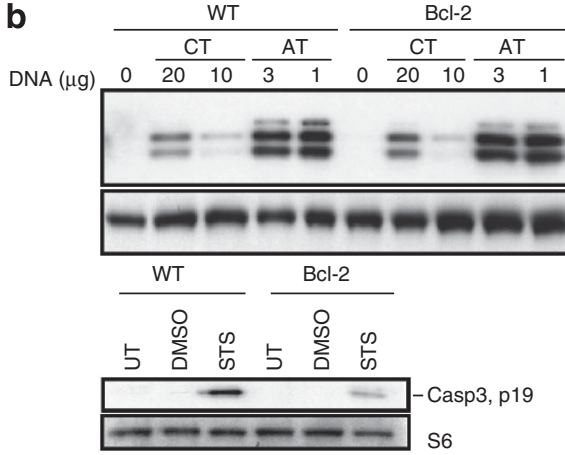

C

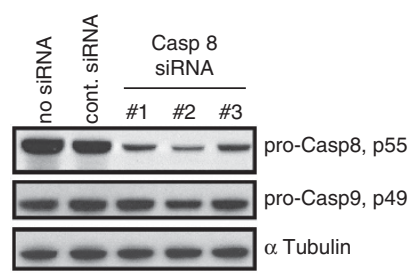

d

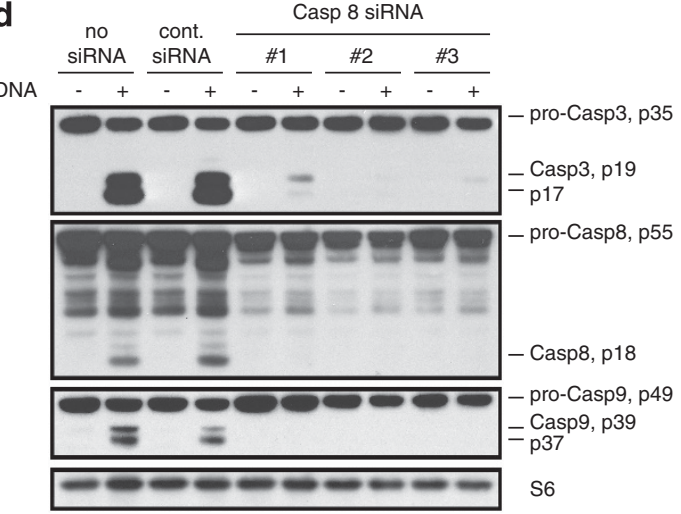

e

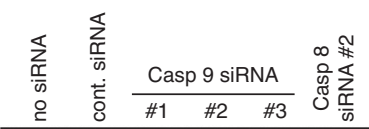

$\longrightarrow$ pro-Casp9, p49

$\longrightarrow$ pro-Casp8, p55

$\alpha$ Tubulin

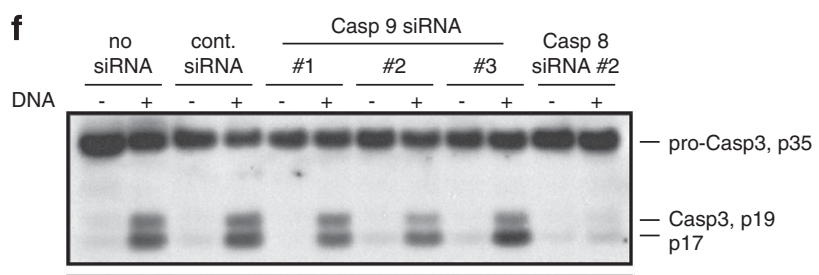

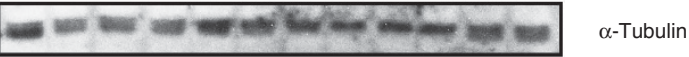

g

No DNA
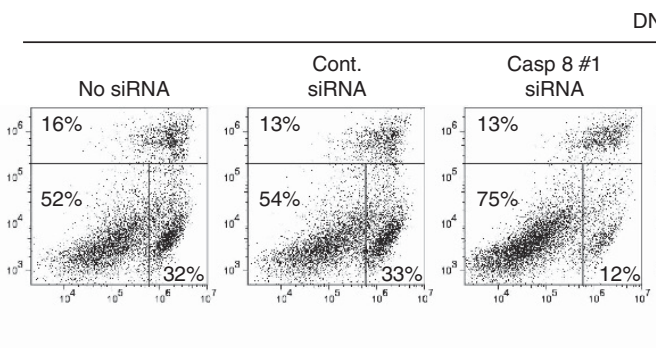

DNA
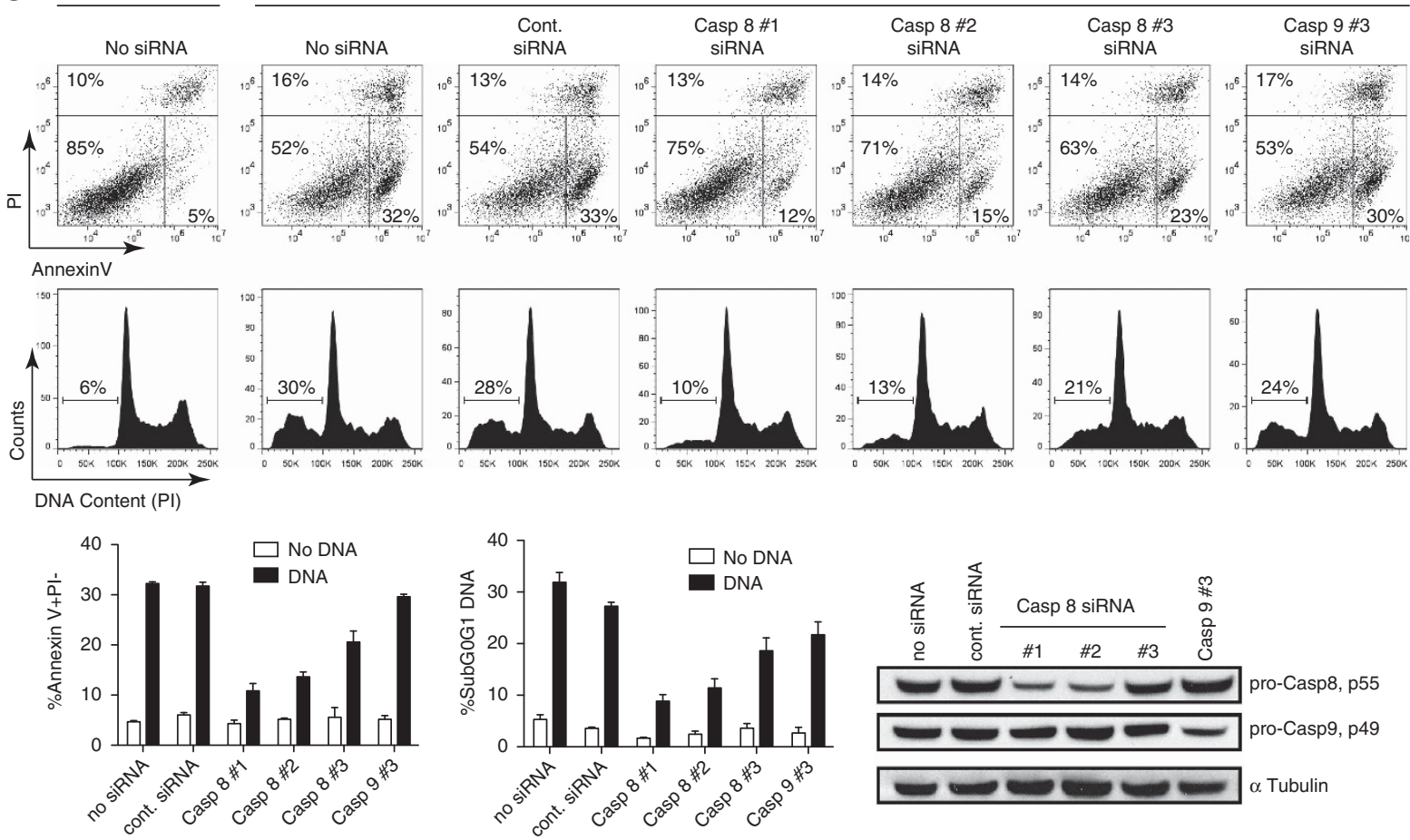

pro-Casp8, p55

pro-Casp9, p49

$\longrightarrow 000$ Tubulin 
on priming by LPS (Supplementary Figure 3). Consistent with an inflammasome-induced apoptotic pathway, ASC-dependent caspase- 8 and -3 processing was observed in the WT and Casp1 $^{-1-}$ cells (Figure $5 \mathrm{~d}$ ). Knockdown of caspase-8, but not caspase-9, prevented caspase-3 cleavage in response to nigericin (Figure 5e). The degree of knockdown in this experiment is shown in Figure $4 \mathrm{~g}$. Finally, knockdown of caspase-8, but not caspase-9, prevented the death of the Casp1 $1^{-/-}$cells (Figure 5f). Thus both the AIM2 and NLRP3 inflammasomes, which recruit ASC, are able to activate caspase- 8 and initiate apoptosis, in addition to caspase-1-dependent pyroptosis.

Procaspase-8 colocalises with ASC in cells. It has been shown that an ectopic FLAG-tagged caspase-8 DED prodomain associated with ASC specks upon Francisella infection. ${ }^{21}$ Here we investigated the localisation of endogenous procaspase-8 and ASC in Casp1-/- macrophages stimulated with an NLRP3 agonist by confocal immunofluorescence microscopy. In the absence of a stimulus, ASC was predominantly nuclear, whereas caspase-8 localised to the cytoplasm (Figure 6a, lower panel). Cells were treated with $5 \mu \mathrm{M}$ nigericin in the presence of the pan-caspase inhibitor Z-VAD-FMK to inhibit cleavage of procaspase-8 and prolong interactions dependent on its DED pro-domain. In treated cells, ASC was detected almost exclusively in cytoplasmic specks (Figure 6a, upper panel). Caspase-8 maintained cytoplasmic localisation, but also formed small specks of more intense staining, which colocalised with ASC. Thus, endogenous procaspase-8 clearly colocalised with ASC upon inflammasome stimulation.

ASC pyrin domain binds to procaspase-8. To determine whether ASC might recruit procaspase-8, we investigated the interaction between these two proteins. Immunoprecipitation experiments have shown ASC and caspase- 8 as part of a complex within cells, ${ }^{36}$ but that does not exclude the involvement of other proteins. We analysed the pull-down of in vitro-translated procaspase-8 using recombinant GST-pyrin or GST-CARD domains of ASC. Procaspase-8 was recovered from the solution using GST-pyrin immobilised on beads, but not GST-CARD or a GST control (Figure 6b). Additional controls performed to confirm specificity showed that procaspase-8 does not bind to the pyrin domains of NLRP3 or POP1, or to the death domain (DD) of Fas (Supplementary Figure 6).

\section{Discussion}

The inflammasome is a platform for activation of caspase-1, which subsequently leads to lytic pyroptotic death. We have shown here that caspase-8-dependent apoptosis is an additional pathway resulting from inflammasome activation. Cleaved forms of apical caspase-8 and executioner caspase3 were seen with the AIM2 and NLRP3 inflammasome in response to cytosolic DNA and nigericin, respectively. This processing was independent of caspase-1 but dependent on the inflammasome adapter ASC. A recent complementary work $^{21}$ showed that infection of macrophages with Francisella tularensis initiated AIM2-dependent apoptosis in caspase-1knockout cells. Another recent work has shown ASC-dependent cleavage of caspase-3 in response to NLRC4 inflammasome activation by Legionella pneumophila, ${ }^{37}$ and in a separate study, apoptosis was induced by inflammasome responses to Salmonella enterica in Casp $1^{-/-}$cells. ${ }^{38}$ Thus inflammasomedependent apoptosis is relevant to infectious agents. Absence of caspase-1 prevents pyroptosis and allows apoptosis to be more clearly observed. However, inflammasome-dependent apoptosis is not restricted to cells lacking caspase-1 and is also seen in WT cells. The balance between apoptosis and pyroptosis depended on the strength of the signal. Pyroptosis had a higher threshold for initiation and apoptosis predominated at lower DNA concentrations. Apoptotic responses to inflammasome activation may be missed in many experimental settings, due to the dominance of rapid pyroptosis at the high concentrations of stimuli that are generally used.

Activation of AIM2 or NLRP3 inflammasomes induced the cleavage of apoptotic initiator caspase-8 and -9 , and executioner caspase-3 and -7. Gene silencing showed that caspase- 8 was the apical caspase in the apoptotic pathway. A previous work had similarly suggested that caspase- 8 was the apical caspase in the AIM2 response to Francisella. ${ }^{21}$ The authors also proposed an important role of caspase- 9 and the intrinsic apoptotic pathway in response to Francisella in $\mathrm{Casp1}^{-/-}$cells, based largely on the results of $\mathrm{Bcl}-2$ overexpression. Our knockdown data in $\mathrm{Casp1}^{-/-}$cells suggest that caspase-9 is dispensable for AIM2 or NLRP3 inflammasome-mediated apoptosis. In WT macrophages, we found no evidence for decreased inflammasome-induced caspase-3 cleavage with Bcl-2 overexpression. The differences between the effect of Bcl-2 overexpression presented here and those published by Pierini et al. ${ }^{21}$ may be attributed

Figure 4 Caspase-8 is the apical apoptotic caspase activated by the DNA inflammasome. (a) Caspase-2 is not involved in DNA-dependent caspase-3 cleavage. WT C57BL/ 6 and Casp2 ${ }^{-\prime-}$ BMMs were electroporated with either $20 \mu \mathrm{g}$ of CT DNA (CT) or $2 \mu \mathrm{g}$ of poly(dA):(dT) (AT), and harvested after 30 min. Some cells were subjected to incubation at $43^{\circ} \mathrm{C}$ for $1 \mathrm{~h}$ to induce a heat-shock response as a positive control for caspase-2 activation. Cleaved caspase-3 and total caspase-2 were detected by western blotting. (b) No evidence for the intrinsic pathway in DNA-dependent caspase-3 cleavage. C57BL/6 (WT) and Bcl-2-overexpressing BMMs were electroporated with the stated doses of either CT DNA (CT) or poly(dA):(dT) (AT), or left untreated. Cell extracts were prepared 30 min after electroporation and the level of cleaved caspase-3 was detected by western blotting. As shown in the lower panel, the effect of $\mathrm{Bcl}-2$ overexpression was confirmed by inhibition of the response to STS. Cells were either untreated (cont.) or treated with $1 \mu \mathrm{M}$ STS or a DMSO vehicle control for $3 \mathrm{~h}$ prior to preparation of extracts for western blotting. (c) Knockdown of caspase-8 for $28 \mathrm{~h}$, using three different siRNAs in Casp1 ${ }^{-/-}$iBMMs, assessed by western blot. (d) Caspase-8 is essential for DNA-dependent caspase-3 cleavage. Casp $1^{-1-}$ iBMMs with caspase-8 knocked down, from the experiment shown in panel c, were electroporated with $10 \mu \mathrm{g}$ of DNA and lysed after $30 \mathrm{~min}$ for analysis by western blot. (e) Knockdown of caspase-9 using three different siRNAs, and caspase-8 using a single siRNA, in Casp $1^{-1-}$ iBMMs, assessed by western blot after $28 \mathrm{~h}$. (f) Caspase-9 has little or no role in DNA-dependent caspase-3 cleavage. Casp $1^{-1-}$ iBMMs with caspase- 9 or -8 knocked down, from the experiment shown in panel e, were treated and analysed as per panel $\mathbf{d}$. (g) Knockdown of caspase-8 prevents DNA-dependent apoptosis. The degree of caspase- 8 and -9 knockdown in this experiment, as assessed by western blot, is shown in the lower right-hand panel. Casp1 $1^{-1-}$ iBMMs with caspase-8 or -9 knocked down were analysed for DNA-dependent apoptosis by Annexin-V-PI staining and sub-G $\mathrm{G}_{0} \mathrm{G}_{1}$ DNA content at 1.5 and $6 \mathrm{~h}$, respectively, post electroporation using $10 \mu \mathrm{g}$ of DNA. Representative primary data are shown, and the graphs show the mean and range of duplicate electroporations. Inhibition of apoptosis by caspase-8 knockdown was shown in three separate experiments 

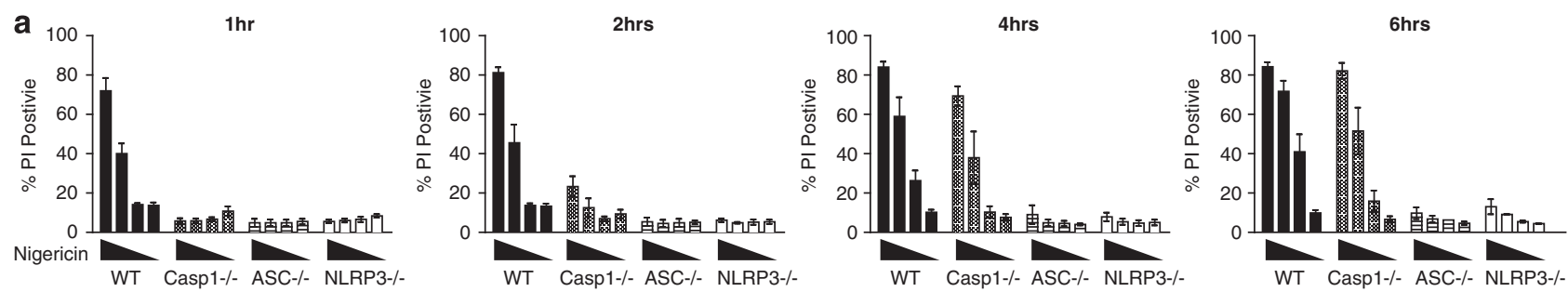

b
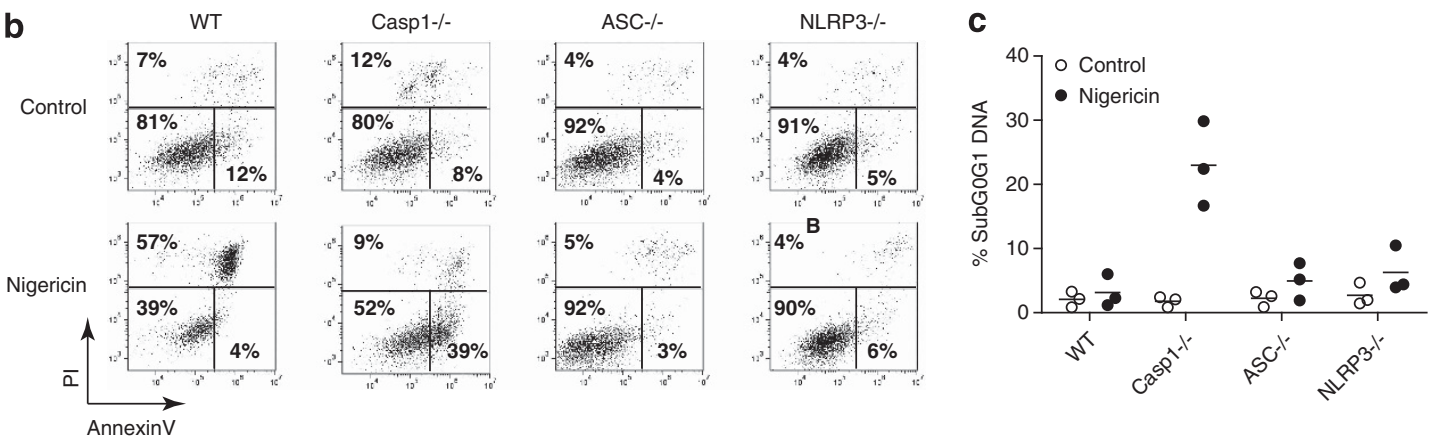

d

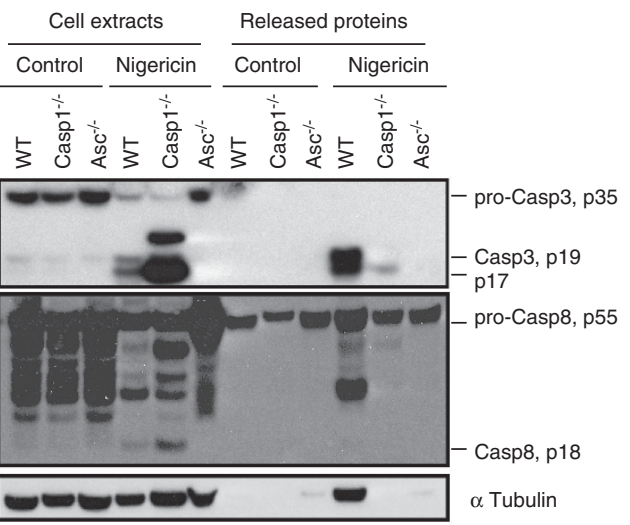

e
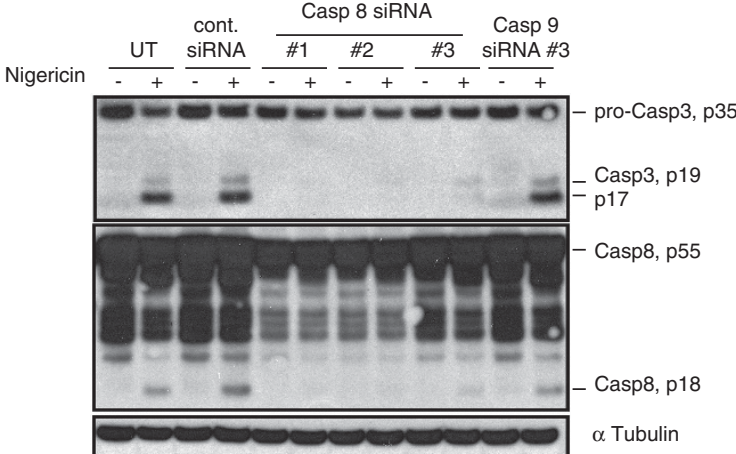
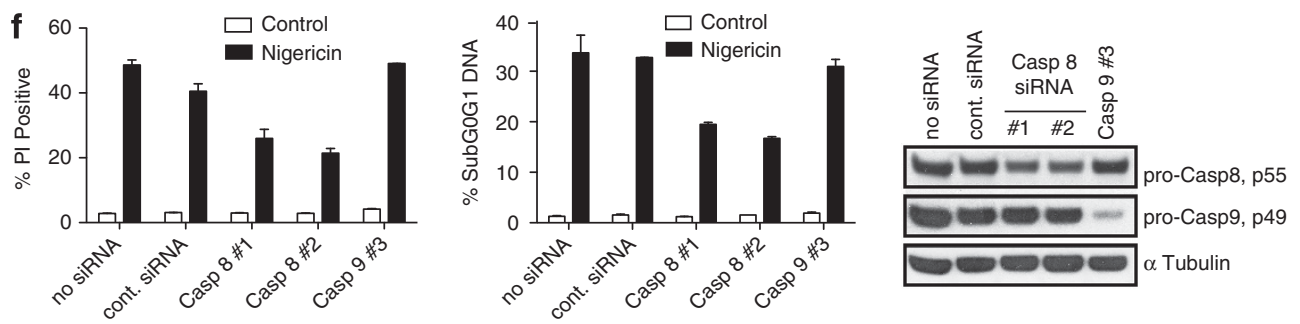

Figure 5 NLRP3 inflammasome agonist nigericin induces apoptosis in a caspase-8-dependent manner. (a) Nigericin-induced cell death is delayed in Casp $1^{-/-}$BMMs. BMMs of the indicated genotypes were primed for $4 \mathrm{~h}$ with $10 \mathrm{ng} / \mathrm{ml} \mathrm{LPS} \mathrm{prior} \mathrm{to} \mathrm{treatment} \mathrm{for} 1-6 \mathrm{~h}$ with nigericin at doses $0,2.5,5$ and $10 \mu \mathrm{M}$. The degree of cell death was determined by PI staining followed by flow cytometry. The results shown are the means \pm S.E. of the data of three independent experiments. (b) Nigericin causes pyroptotic death of WT cells and apoptotic death of Casp1 ${ }^{-/-}$BMMs. BMMs were treated with $10 \mathrm{ng} / \mathrm{ml} \mathrm{LPS}$, followed by $10 \mu \mathrm{M}$ nigericin for $2 \mathrm{~h}$. Annexin-V-PI staining was used to detect apoptotic cells by flow cytometry. (c) Apoptotic death of Casp $1^{-1-}$ BMMs was detected by the presence of sub- $G_{0} / G_{1}$ DNA content. Cells were primed with $10 \mathrm{ng} / \mathrm{ml}$ LPS for $4 \mathrm{~h}$, followed by nigericin for $6 \mathrm{~h}$. Each data point shows the result of an independent experiment. (d) Nigericin activates apoptotic caspases in an ASC-dependent and caspase-1-independent manner. BMMs from C57BL/6 (WT), $A s c^{-1-}$ and Casp ${ }^{-1-}$ mice were pretreated with $10 \mathrm{ng} / \mathrm{ml} \mathrm{LPS}$ and after $4 \mathrm{~h}$ nigericin was added to the cells at a final concentration of $10 \mu \mathrm{M}$. Control cells were treated with a methanol vehicle control. Cell protein extracts and proteins released into the culture medium were collected after $2.5 \mathrm{~h}$ of incubation at $37^{\circ} \mathrm{C}$, and analysed by western blot. (e) Caspase-8 is the apical apoptotic caspase activated by nigericin. Casp $1^{-/-}$iBMMs with caspase-8 or -9 knocked down were treated with $100 \mathrm{ng} / \mathrm{ml}$ LPS for $4 \mathrm{~h}$ followed by $10 \mu \mathrm{M}$ nigericin for $75 \mathrm{~min}$. Cell extracts were analysed by western blot. The degree of knockdown in this experiment is shown in Figure 4g. (f) Nigericin-dependent apoptosis requires caspase-8. Casp $1^{-1-}$ iBMMs with caspase-8 or -9 knocked down were treated with $10 \mathrm{ng} / \mathrm{ml}$ LPS for $4 \mathrm{~h}$ followed by $10 \mu \mathrm{M}$ nigericin for $4 \mathrm{~h}$. The results shown are the mean and range of duplicate cell treatments from a single experiment. An effect of caspase-8 knockdown was shown in four independent experiments. The left-hand panel shows cell death measured by flow cytometry of PI-stained cells; the middle panel shows sub- $G_{0} / G_{1}$ cells assessed by flow cytometry as an indication of apoptosis; and the right hand panel shows the degree of caspase- 8 and -9 knockdown, assessed by western blot. Example primary data from flow cytometry are shown in Supplementary Figure 4 
a
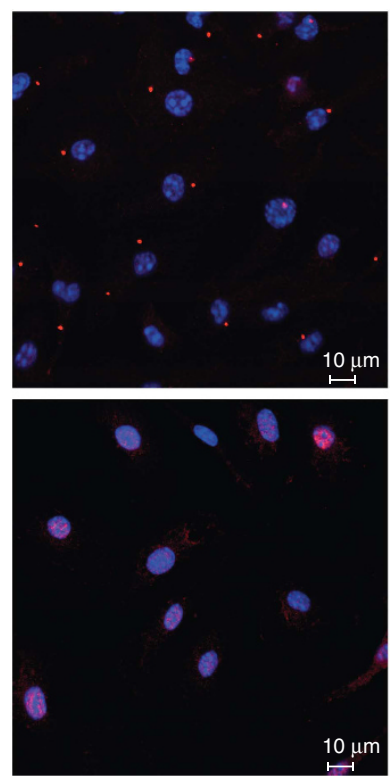

Casp8/DAPI
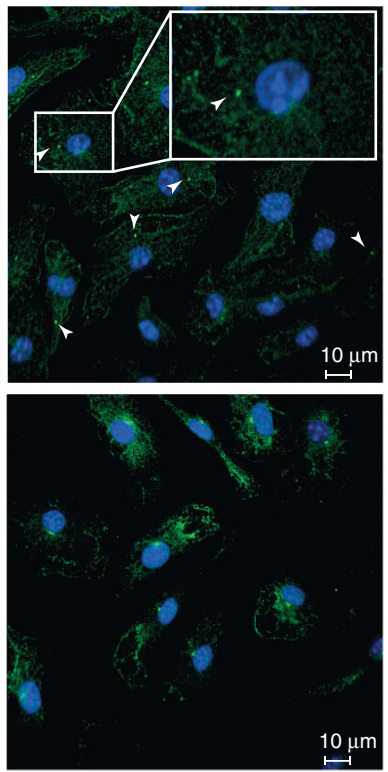
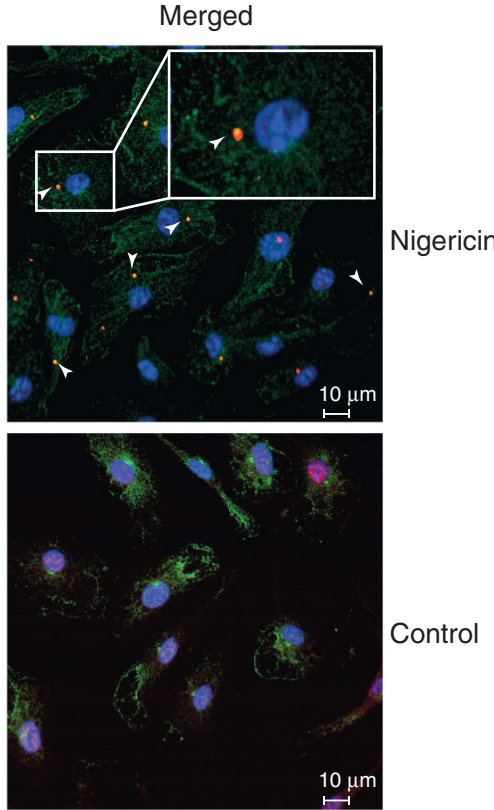

b

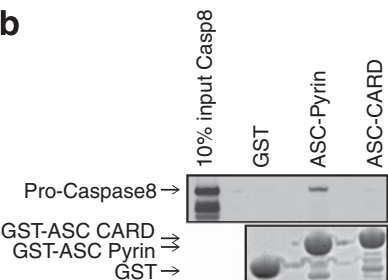

Figure 6 Procaspase-8 colocalises with ASC and directly interacts with the ASC pyrin domain. (a) Procaspase-8 colocalises with ASC upon inflammasome induction with nigericin. Casp1 ${ }^{-1}$ BMMs were pre-treated with LPS and Z-VAD-FMK prior to inflammasome stimulation with $5 \mu \mathrm{M}$ nigericin (upper panel) or treatment with an ethanol vehicle control (lower panel). Cells were stained with anti-ASC (red) and anti-caspase-8 (green), and nuclei were counterstained with DAPI (blue). The arrows indicate examples of caspase-8 specks colocalised with ASC. The data shown are representative of two independent experiments and represent the appearance of the majority of the cells under the stated conditions. (b) Pull-down of procaspase-8 by ASC pyrin and ASC CARD domains. Bead-immobilised recombinant GST-ASC-pyrin, GST-ASC-CARD and a GST control were used to pull down $\left[{ }^{35}\right.$ S]-labelled in vitro translated procaspase-8 (catalytic site mutant). Loading of beads with GST proteins was shown by SDS-PAGE and protein stain (lower panel), and the pulled down procaspase-8 was detected with an X-ray film (upper panel). Similar results were seen in three experiments. Lack of binding to other DDs is shown in Supplementary Figure 6

to the action of bacterial factors that confine caspase-8 activity. Alternatively, the Casp $1^{-1-}$ cells used in their study may have greater dependence than WT cells on some effects of the intrinsic pathway, such as mitochondrial release of SMAC to reinforce caspase-8 activation.

ASC is the key molecule orchestrating the recruitment of both procaspase- 1 and -8 to the inflammasome complex (Figure 7). An interaction between procaspase-8 and ASC has some precedent in the literature: ectopic procaspase-8 was immunoprecipitated from HEK293 cell extracts in a complex with overexpressed ASC pyrin domain but not CARD domain. ${ }^{36}$ In addition, upon overexpression, the DED domains of procaspase-8 mediated colocalisation with the AIM2 inflammasome in Francisella-infected cells. ${ }^{21}$ Together with our work, this strongly implicates a direct interaction between the DEDs of procaspase-8 and the pyrin domain of ASC. The DD superfamily includes CARD, DED, pyrin (PYD) and DDs, which are prominent in signalling pathways of innate immunity as well as cell death. ${ }^{15}$ Reported interactions between DDs are almost exclusively homotypic, although CARD-DD and CARD-DED interactions have been observed. ${ }^{39,40}$
Interestingly, phylogenetic analysis of protein sequences shows that the pyrin domains and DEDs shown to interact here form a clade, and are more distantly related to the other DDs. ${ }^{15}$

ASC was first named 'apoptosis-associated speck-like protein containing a CARD' due to clustering of ASC seen in HL60 cells induced to undergo apoptosis by chemotherapeutic agents. ${ }^{41}$ In addition, ASC was independently described as a candidate tumour-suppressor protein 'target of methylationinduced silencing-1' (TMS1) ${ }^{42}$ and is silenced in approximately $40 \%$ of breast cancers. ${ }^{43}$ Literature on the role of ASC in tumour cell apoptosis has been largely ignored within the inflammasome literature, and vice versa. Although studies have assumed that a tumour-suppressor function of ASC relies on a connection with apoptotic pathways, suggested mechanisms vary. Studies of tumour cells have suggested that ASC-dependent apoptosis requires ASC interaction with the $\mathrm{Bcl}-2$ family member Bax, ${ }^{44}$ or caspase-8. ${ }^{36,45}$ In a parallel with our work here, forced ASC clustering led to either apoptotic or necrotic death of tumour cells, depending on their expression of caspase-1. ${ }^{45}$ The tumour-related literature has 


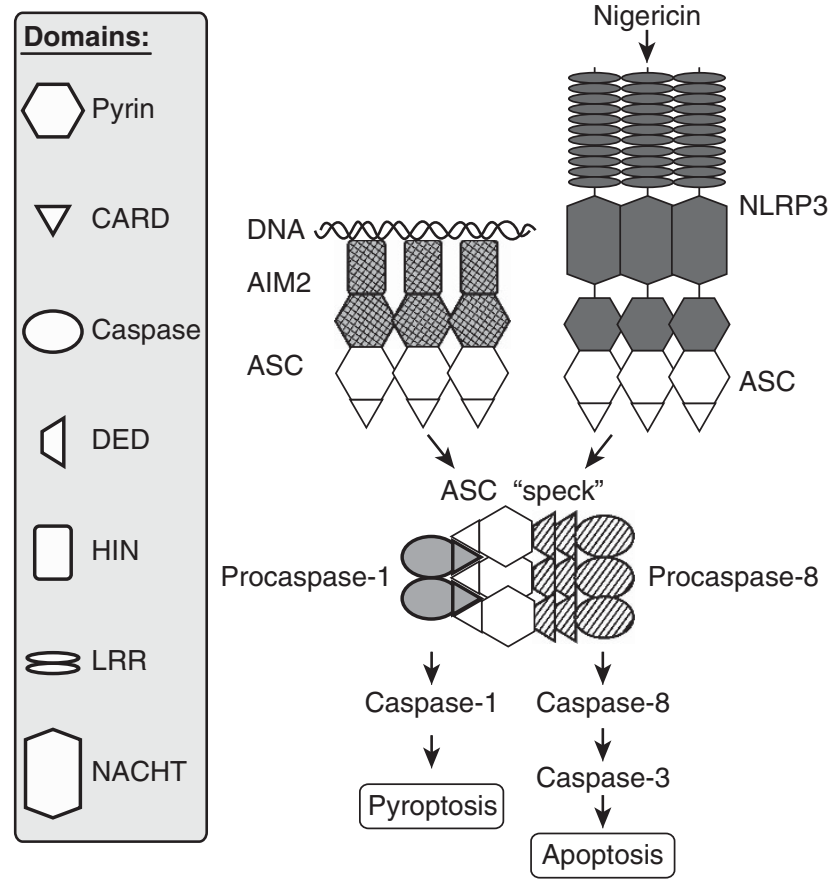

Figure 7 A model for the AIM2 and NLRP3 inflammasomes, activating parallel apoptotic and pyroptotic death pathways. DNA in the cytosol is recognised by the HIN domain of AIM2. ${ }^{10-13}$ Binding of AIM2 along the length of the DNA then recruits ASC via homotypic pyrin domain interactions. This then nucleates the formation of a cluster of ASC, which self-associates via both pyrin and CARD domain interactions. ${ }^{61}$ The ASC cluster may lose association with AIM2, as it has been observed in cells adjacent to the AIM2-DNA complex. ${ }^{18}$ Alternatively, nigericin leads to NLRP3 clustering and nucleation of an ASC speck. ASC is an adapter molecule that recruits procaspase-1 via homotypic CARD domain interactions. Clustering leads to activation of procaspase-1, which promotes pyroptosis. The alternative pathway elucidated here involves recruitment of procaspase-8 via the pyrin domain of ASC and its activation, leading to downstream caspase-3 cleavage and apoptotic cell death. Whether both procaspase- 1 and -8 can be recruited to the same ASC molecule as shown here has not been established, although since they bind to different domains, this is feasible

not established physiological stimuli lying upstream from ASC clustering and induction of apoptosis. We suggest that conventional inflammasomes may have tumour-suppressor functions, and ways in which malignancy can be detected via known inflammasomes in a tumour cell-intrinsic manner deserve consideration.

We have shown cleavage of caspase- 8 and -1 initiated by the AIM2 and NLRP3 inflammasomes, and two reports have shown that another inflammasome initiator protein, NLRC4 (IPAF), when constitutively activated by truncation, also causes cleavage of both caspases. ${ }^{36,46}$ Activation of several death pathways simultaneously could be a cellular attempt to avoid inhibition of cell death by pathogens. In the case of recognition of viral DNA, the virus would need to inhibit pathways activated by both caspase- 8 and -1 . This is indeed achieved by CrmA from cowpox virus, which inhibits both these caspases. ${ }^{47}$

In summary, recruitment and activation of procaspase-8, and induction of apoptosis, can be considered an intrinsic part of inflammasome function. This extends the relevance of inflammasome responses beyond cell types expressing caspase-1. We suggest that normal inflammasome responses, such as detection of abnormal cytosolic DNA, may explain the identification of both AIM2 and ASC as candidate tumour suppressors. ${ }^{43,48,49}$

\section{Materials and Methods}

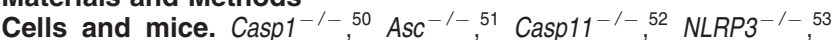
$\mathrm{C} 57 \mathrm{BL} / 6$ and vav-Bcl-2 transgenic mice ${ }^{54}$ were housed under specific pathogenfree (Spf) conditions and used under approval from the University of Queensland animal ethics committee. Casp2 ${ }^{-1-}$ mice $^{55}$ were used at Latrobe University, Melbourne, under ethical approval from the Latrobe animal ethics committee. Knockout mice were made using ES cells derived from 129 strain mice and backcrossed onto the C57BL/6 background. The vav- $\mathrm{BCl}-2$ transgenic was made using C57BL/6 cells. BMMs were obtained from these strains as described ${ }^{56}$ and used after 7-10 days of differentiation. Casp 1 ${ }^{-1-}$ BMMs immortalised with $v$-myc and $v$-raf/mil oncogenes ${ }^{57}$ were obtained from Eicke Latz and Kate Fitzgerald (University of Massachusetts Medical School). Cells were maintained on bacteriological plates in RPMI1640 medium with 10\% heat-inactivated foetal calf serum (FCS), $100 \mathrm{U} / \mathrm{ml}$ penicillin and $100 \mu \mathrm{g} / \mathrm{ml}$ streptomycin.

Chemicals and DNAs. CT DNA (Sigma St. Louis, MN, USA) and doublestranded homopolymer polydA:polydT (GE Healthcare, Little Chalfont, UK) were purified with Triton X-114 to ensure absence of LPS, as described.$^{58}$ Salmonella minnesota Re595 LPS was obtained from Sigma and used at $10 \mathrm{ng} / \mathrm{ml}$. Ultrapure LPS from Escherichia coli K12 was obtained from Invivogen (San Diego, CA, USA) and used at $100 \mathrm{ng} / \mathrm{ml}$. Z-VAD-FMK was obtained from Calbiochem (Merck Millipore, Billerica, MA, USA), and nigericin and STS were from Sigma. Nigericin was dissolved in either methanol or ethanol, and the solvent used as vehicle control in experiments.

Electroporation and MTT assay. Cells were electroporated with DNA in a total volume of $400 \mu \mathrm{l}$ of full growth medium, unless otherwise noted, in $0.4-\mathrm{cm}$ cuvettes using a Bio-Rad Gene Pulser set at $1000 \mu \mathrm{F}, 240 \mathrm{~V}$. Cleavage of MTT reagent (Sigma) by the mitochondrial enzyme succinate dehydrogenase was used as a measure of cell viability. Assays were performed as described ${ }^{59}$ using 120000 cells per well. Where cells were non-adherent, they were incubated in $60 \mu \mathrm{l}$ of medium with $1 \mathrm{mg} / \mathrm{ml}$ MTT for $1 \mathrm{~h}$ and the product was solubilised by addition of $200 \mu \mathrm{l}$ of $10 \%$ SDS and $50 \%$ isopropanol overnight.

Flow cytometric determination of apoptosis. For staining with Annexin-V combined with $\mathrm{Pl}, 250000$ cells were resuspended in $50 \mu \mathrm{l}$ of $10 \mathrm{mM}$ HEPES (pH 7.4), $140 \mathrm{mM} \mathrm{NaCl}$ and $2.5 \mathrm{mM} \mathrm{CaCl}_{2}$, and placed on ice for $5 \mathrm{~min}$. A further $50 \mu \mathrm{l}$ of buffer containing $5 \mu \mathrm{l}$ of Annexin V-Alexa Fluor-488 (Life Technologies, Grand Island, NY, USA) was added, mixed and incubated on ice in dark for $10-15 \mathrm{~min}$. A $400-\mu$ l volume of buffer containing $0.6 \mu \mathrm{g} / \mathrm{ml} \mathrm{PI}$ (Life Technologies) was added and samples were analysed on a C6 Accuri cytometer. Sub- $G_{0} / G_{1}$ DNA was analysed using PI as described. ${ }^{56}$

Protein extracts and western blotting. Where proteins were analysed in both cell lysate and medium, cells were washed at RT immediately after electroporation to remove any debris, and resuspended in serum-free medium. After incubation at $37^{\circ} \mathrm{C}$, cells were pelleted and lysed in $2 \%$ SDS and $62 \mathrm{mM}$ Tris $(\mathrm{pH}$ 6.8). Extracellular proteins were concentrated from the medium using four volumes of $100 \%$ acetone and centrifugated at $17000 \times g$. Western blotting was performed as described. ${ }^{13}$ The primary antibodies used were as follows: rabbit polyclonal antibodies against full-length caspase-3 (\#9662) and cleaved caspase-3 (\#9661), which were used together; rabbit polyclonal antibodies against caspase-9 (\#9508), caspase-7 (\#9492), IL-1 $\beta$ (\#8689), and mouse monoclonal antibodies against S6 ribosomal protein, clone 54D2 (Cell Signaling Technologies, Boston, MA, USA), rat monoclonal anti-caspase-8, clone $1 \mathrm{G} 12,{ }^{60}$ and anti-caspase-2, clone 11B4 (Enzo Life Sciences, Farmingdale, NY, USA), rabbit polyclonal anticaspase-1 (M-20) (Santa Cruz Biotechnology, Santa Cruz, CA, USA), anti- $\alpha-$ tubulin, clone B-5-1-2 (Sigma) and anti-PARP1, clone A6.4.12 (Serotec, Raleigh, NC, USA). Horseradish peroxidase (HRP)-linked secondary antibodies were obtained from Cell Signaling Technologies. Sequential reprobing of membranes with different antibodies was performed after inactivation of HRP by $0.1 \% \mathrm{NaN}_{3}$ in $10 \mathrm{mM}$ Tris $(\mathrm{pH} 7.4), 15 \mathrm{mM} \mathrm{NaCl}$ and $0.05 \%$ Tween-20 where possible, or otherwise after stripping of antibodies from membranes by three 10-min washes with $66 \mathrm{mM}$ Tris (pH 6.8), $2 \%$ SDS and $0.1 \mathrm{M} \beta$-mercaptoethanol at $50^{\circ} \mathrm{C}$. 
In some cases, duplicate blots of the same samples were run and probed with different antibodies, and these are shown together in one figure. Loading controls were performed on all blots and a representative control is shown for each set of samples.

siRNA gene knockdown. Stealth siRNAs were obtained from Life Technologies. Sequences targeted in caspase-8 mRNA were: siRNA \#1: 5'-GGUGACAAGGGUGUCGUCUAUGGAA-3', siRNA \#2: 5'-GGCGUGAACUAU GACGUGAGCAAUA-3' and siRNA \#3: $5^{\prime}$-UCACACUACGGAAGAAGCUCUUC UU-3', and in caspase-9 mRNA were: siRNA \#1: 5'-ACAGCCAGGAAUCU GCUUGUAAGUC-3', siRNA \#2: 5'-UGGGACCAAUGGGACUCACAGCAAA-3' and siRNA \#3: 5'-ACAGCCAGGAAUCUGCUUGUAAGUC-3'. The control siRNA targeted mouse TLR9: 5'-GCCAGCCCUUUAGCAUGAAGGGUAU-3': Cells were electroporated as per DNA, but at $260 \mathrm{~V}$, with $0.75 \mu \mathrm{M}$ siRNAs. The degree of knockdown was assessed and cells were used for experiments $27 \mathrm{~h}$ after introduction of siRNAs.

Immunofluorescence staining and confocal microscopy. For immunofluorescence staining, BMMs were grown on glass coverslips. Cells were treated for $3 \mathrm{~h}$ with $10 \mathrm{ng} / \mathrm{ml}$ LPS and $1 \mathrm{~h}$ with $25 \mu \mathrm{M}$ pan-caspase inhibitor Z-VAD-FMK prior to inflammasome induction using $5 \mu \mathrm{M}$ nigericin for $45 \mathrm{~min}$. The cells were fixed with $1 \%$ paraformaldehyde (PFA) prepared in $1 \times$ PBS supplemented with $\mathrm{Ca}^{2+}$ and $\mathrm{Mg}^{2+}$ for $10 \mathrm{~min}$ at $\mathrm{RT}$ and then permeabilised/ blocked for $45 \mathrm{~min}$ at RT in PBS/ $/ \mathrm{Ca}^{2+} \mathrm{Mg}^{2+}$ containing $10 \% \mathrm{FCS}$ and $0.3 \%$ saponin (Sigma). Cells were incubated overnight at $4{ }^{\circ} \mathrm{C}$ with rat monoclonal anticaspase-8, clone $3 \mathrm{~B}^{10} 0^{60}$ (Enzo Life Sciences), and/or rabbit polyclonal anti-ASC (N-15) (Santa Cruz Biotechnology) diluted in antibody incubation buffer $(1 \times \mathrm{PBS} /$ $\mathrm{Ca}^{2+} \mathrm{Mg}^{2+}$ with $2.5 \% \mathrm{FCS}$ and $0.3 \%$ saponin). Unbound antibodies were washed with $\mathrm{PBS} / \mathrm{Ca}^{2+} \mathrm{Mg}^{2+}$ containing $0.05 \%$ Tween-20 and slides were incubated for $1 \mathrm{~h}$ at RT with secondary antibodies, goat anti-rat-Alexa Fluor-488 and chicken-anti-rabbit-Alexa Fluor-647 (Life Technologies), diluted in antibody incubation buffer supplemented with $0.2 \mu \mathrm{g} / \mathrm{ml} \mathrm{4',6-diamidino-2-phenylindole}$ (DAPI) to stain nuclei. The slides were mounted in fluorescent mounting medium (Dako, Glostrup, Denmark). The cells were examined with an LSM510 laserscanning confocal microscope using the Zen2009 software (Carl Zeiss, Oberkochen, Germany). Pinhole size was adjusted to get the same axial resolution for different channels. Fluorescent signal bleeding or cross-reactivity of secondary antibodies was ruled out by labelling the cells with a primary antibody against ASC or caspase-8 alone (Supplementary Figure 5). All experimental and control images were collected using identical imaging settings.

Protein expression and purification. For expression in $E$. coli with an $\mathrm{N}$-terminal GST tag, CDNA fragments encoding the human ASC pyrin domain (residues 1-91) and the human ASC CARD (residues 105-195) were subcloned into pGEX-4T-1 (GE Healthcare). The resulting plasmids were transformed into E. coli BL21. To express GST-fusion proteins, E. coli were grown at $37^{\circ} \mathrm{C}$ to optical density $A_{600}=0.7$ and then induced with $1 \mathrm{mM} \mathrm{IPTG}$ at $30^{\circ} \mathrm{C}$ for $1 \mathrm{~h}$. Recombinant proteins were purified using glutathione-agarose beads (Sigma). Full-length human procaspase-8 cDNA was subcloned into pET21a (Merck Millipore). A catalytically inactive mutant (C360S) was prepared using the Quikchange II site-directed mutagenesis kit (Agilent Technologies, Santa Clara, CA, USA). Procaspase-8 (C360S) was synthesised in vitro from the template pET21a-procaspase-8 (C360S) using the TNT T7 Coupled Reticulocyte Lysate System (Promega, Madison, WI, USA) in the presence of $\left[{ }^{35} \mathrm{~S}\right.$ - methionine (PerkinEImer, Waltham, MA, USA).

Protein interaction assay. The ${ }^{35}$ S-labelled procaspase-8 (C360S) was incubated with GST-tagged ASC-pyrin or ASC-CARD bound to glutathioneagarose in $150 \mu \mathrm{l}$ of binding buffer (50 mM HEPES (pH 7.4), $50 \mathrm{mM} \mathrm{NaCl}, 5 \mathrm{mM}$ EDTA, $0.1 \%$ NP- $40,10 \%$ glycerol). Samples were incubated for $2 \mathrm{~h}$ at $4{ }^{\circ} \mathrm{C}$ and washed three times with $0.5 \mathrm{ml}$ of binding buffer. Bound protein was eluted with SDS-PAGE sample buffer and separated by SDS-PAGE. Proteins on the gel were detected using the Simply Blue Safe stain (Life Technologies) and ${ }^{35}$ S-labelled procaspase-8 was detected using an X-ray film (Fuji, Tokyo, Japan).

\section{Conflict of Interest}

The authors declare no conflict of interest.
Acknowledgements. We thank Ben Croker for supplying Casp11 $11^{-1}$ and $A s C^{-/-}$mice; Odilia Wijburg for Casp $1^{-/-}$mice; Jerry Adams and Mark Smyth for vav-Bcl-2 mice; and Richard Flavell, Vishva Dixit (Genentech) and Junying Yuan

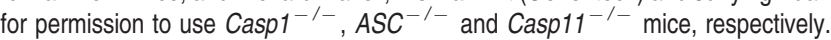
Immortalised BMMs were provided by Kate Fitzgerald and Eicke Latz. We acknowledge the support received from the Australian Infectious Diseases Research Centre to undertake this work. KJS is supported by Australian Research Council Future Fellowship FT0991576. The research was supported by National Health and Medical Research Council grants 631472 and 1010887.

\section{Author Contributions}

All authors read and approved the manuscript. VS: Project direction, cell death assays, western blots, gene knockdown, immunofluorescence and confocal microscopy, writing of the manuscript; ST: Western blots, gene knockdown, cell death assays; DPS: Project direction, cell death assays; Al: caspase-2, Bcl-2, temperature dependence data; JAC: Protein interaction studies, western blots, cell death assays, immunofluorescence, confocal microscopy; JEV, PRV and JMH: Protein interaction studies; TLR, KS and JS: Supervision, intellectual input; KJS: Project conception and design, cell death assays, gene knockdown, manuscript preparation.

1. Schroder K, Tschopp J. The inflammasomes. Cell 2010; 140: 821-832.

2. Bergsbaken T, Fink SL, Cookson BT. Pyroptosis: host cell death and inflammation. Nat Rev Microbiol 2009; 7: 99-109.

3. Miao EA, Rajan JV, Aderem A. Caspase-1-induced pyroptotic cell death. Immunol Rev 2011; 243: 206-214.

4. Fink SL, Cookson BT. Caspase-1-dependent pore formation during pyroptosis leads to osmotic lysis of infected host macrophages. Cell Microbiol 2006; 8: 1812-1825.

5. Strasser A, Cory S, Adams JM. Deciphering the rules of programmed cell death to improve therapy of cancer and other diseases. EMBO J 2011; 30: 3667-3683.

6. Pop C, Salvesen GS. Human caspases: activation, specificity, and regulation. J Biol Chem 2009; 284: 21777-21781.

7. Yazdi AS, Guarda G, D'Ombrain MC, Drexler SK. Inflammatory caspases in innate immunity and inflammation. J Innate Immun 2010; 2: 228-237.

8. Mace PD, Riedl SJ. Molecular cell death platforms and assemblies. Curr Opin Cell Biol 2010; 22: 828-836.

9. van Raam BJ, Salvesen GS. Proliferative versus apoptotic functions of caspase-8 Hetero or homo: the caspase-8 dimer controls cell fate. Biochim Biophys Acta 2012; 1824: 113-122.

10. Burckstummer T, Baumann C, Blum S, Dixit E, Durnberger G, Jahn $\mathrm{H}$ et al. An orthogonal proteomic-genomic screen identifies AIM2 as a cytoplasmic DNA sensor for the inflammasome. Nat Immunol 2009; 10: 266-272.

11. Fernandes-Alnemri T, Yu JW, Datta $P$, Wu J, Alnemri ES. AlM2 activates the inflammasome and cell death in response to cytoplasmic DNA. Nature 2009; 458: 509-513.

12. Hornung V, Ablasser A, Charrel-Dennis M, Bauernfeind F, Horvath G, Caffrey DR et al. AIM2 recognizes cytosolic dsDNA and forms a caspase-1-activating inflammasome with ASC. Nature 2009; 458: 514-518.

13. Roberts TL, Idris A, Dunn JA, Kelly GM, Burnton CM, Hodgson S et al. HIN-200 proteins regulate caspase activation in response to foreign cytoplasmic DNA. Science 2009; 323 : 1057-1060.

14. Cridland JA, Curley EZ, Wykes MN, Schroder K, Sweet MJ, Roberts TL et al. The mammalian PYHIN gene family: phylogeny, evolution and expression. BMC Evol Biol 2012; 12: 140.

15. Kersse K, Verspurten J, Vanden Berghe T, Vandenabeele $P$. The death-fold superfamily of homotypic interaction motifs. Trends Biochem Sci 2011; 36: 541-552.

16. Rathinam VA, Jiang Z, Waggoner SN, Sharma S, Cole LE, Waggoner L et al. The AIM2 inflammasome is essential for host defense against cytosolic bacteria and DNA viruses. Nat Immunol 2010; 11: 395-402.

17. Fernandes-Alnemri T, Yu JW, Juliana C, Solorzano L, Kang S, Wu J et al. The AIM2 inflammasome is critical for innate immunity to Francisella tularensis. Nat Immunol 2010; 11: 385-393

18. Jones JW, Kayagaki N, Broz P, Henry T, Newton K, O'Rourke K et al. Absent in melanoma 2 is required for innate immune recognition of Francisella tularensis. Proc Natl Acad Sci USA 2010; 107: 9771-9776.

19. Warren SE, Armstrong A, Hamilton MK, Mao DP, Leaf IA, Miao EA et al. Cutting edge: cytosolic bacterial DNA activates the inflammasome via Aim2. J Immunol 2010; 185: 818-821.

20. Mariathasan S, Weiss DS, Newton K, McBride J, O'Rourke K, Roose-Girma M et al. Cryopyrin activates the inflammasome in response to toxins and ATP. Nature 2006; 440: 228-232.

21. Pierini R, Juruj $C$, Perret $M$, Jones $C L$, Mangeot $P$, Weiss DS et al. AIM2/ASC triggers caspase-8-dependent apoptosis in Francisella-infected caspase-1-deficient macrophages. Cell Death Differ 2012; 19: 1709-1721

22. Kayagaki N, Warming S, Lamkanfi M, Vande Walle L, Louie S, Dong J et al. Non-canonical inflammasome activation targets caspase-11. Nature 2011; 479: 117-121. 
23. Shelton SN, Dillard CD, Robertson JD. Activation of caspase-9, but not caspase-2 or caspase-8, is essential for heat-induced apoptosis in Jurkat cells. J Biol Chem 2010; 285 : 40525-40533.

24. Zhang XD, Gillespie SK, Hersey P. Staurosporine induces apoptosis of melanoma by both caspase-dependent and -independent apoptotic pathways. Mol Cancer Ther 2004; 3 : 187-197.

25. Varfolomeev EE, Schuchmann M, Luria V, Chiannilkulchai N, Beckmann JS, Mett IL et al. Targeted disruption of the mouse caspase 8 gene ablates cell death induction by the TNF receptors, Fas/Ap01, and DR3 and is lethal prenatally. Immunity 1998; 9: 267-276.

26. Kang TB, Ben-Moshe T, Varfolomeev EE, Pewzner-Jung Y, Yogev N, Jurewicz A et al. Caspase-8 serves both apoptotic and nonapoptotic roles. J Immunol 2004; 173: 2976-2984.

27. Denault JB, Eckelman BP, Shin H, Pop C, Salvesen GS. Caspase 3 attenuates XIAP (X-linked inhibitor of apoptosis protein)-mediated inhibition of caspase 9. Biochem J 2007; 405: 11-19.

28. McDonnell MA, Wang D, Khan SM, Vander Heiden MG, Kelekar A. Caspase- 9 is activated in a cytochrome $c$-independent manner early during TNFalpha-induced apoptosis in murine cells. Cell Death Differ 2003; 10: 1005-1015

29. Vince JE, Wong WW, Gentle I, Lawlor KE, Allam R, O'Reilly L et al. Inhibitor of apoptosis proteins limit RIP3 kinase-dependent interleukin-1 activation. Immunity 2012; 36: 215-227.

30. Gringhuis SI, Kaptein TM, Wevers BA, Theelen B, van der Vlist M, Boekhout T et al. Dectin1 is an extracellular pathogen sensor for the induction and processing of IL-1beta via a noncanonical caspase-8 inflammasome. Nat Immunol 2012; 13: 246-254.

31. Maelfait J, Vercammen E, Janssens S, Schotte P, Haegman M, Magez S et al. Stimulation of Toll-like receptor 3 and 4 induces interleukin-1 beta maturation by caspase-8. J Exp Med 2008; 205: 1967-1973.

32. Bossaller L, Chiang PI, Schmidt-Lauber C, Ganesan S, Kaiser WJ, Rathinam VA et al. Cutting edge: FAS (CD95) mediates noncanonical IL-1beta and IL-18 maturation via caspase-8 in an RIP3-independent manner. J Immunol 2012; 189: 5508-5512.

33. Wewers MD, Winnard AV, Dare HA. Endotoxin-stimulated monocytes release multiple forms of IL-1 beta, including a prolL-1 beta form whose detection is affected by export. $\mathrm{J}$ Immunol 1999; 162: 4858-4863.

34. Bauernfeind FG, Horvath G, Stutz A, Alnemri ES, MacDonald K, Speert D et al. Cutting edge: NF-kappaB activating pattern recognition and cytokine receptors license NLRP3 inflammasome activation by regulating NLRP3 expression. J Immunol 2009; 183: 787-791.

35. Schroder K, Sagulenko V, Zamoshnikova A, Richards AA, Cridland JA, Irvine KM et al. Acute lipopolysaccharide priming boosts inflammasome activation independently of inflammasome sensor induction. Immunobiology 2012; 217: 1325-1329.

36. Masumoto J, Dowds TA, Schaner P, Chen FF, Ogura Y, Li M et al. ASC is an activating adaptor for NF-kappa B and caspase-8-dependent apoptosis. Biochem Biophys Res Commun 2003; 303: 69-73.

37. Abdelaziz DH, Gavrilin MA, Akhter A, Caution K, Kotrange S, Khweek AA et al. Ascdependent and independent mechanisms contribute to restriction of Legionella pneumophila infection in murine macrophages. Front Microbiol 2011; 2: 18.

38. Puri AW, Broz P, Shen A, Monack DM, Bogyo M. Caspase- 1 activity is required to bypass macrophage apoptosis upon Salmonella infection. Nat Chem Biol 2012; 8: 745-747.

39. Nam YJ, Mani K, Ashton AW, Peng CF, Krishnamurthy B, Hayakawa Y et al. Inhibition of both the extrinsic and intrinsic death pathways through nonhomotypic death-fold interactions. Mol Cell 2004; 15: 901-912.

40. Inohara N, Koseki T, del Peso L, Hu Y, Yee C, Chen S et al. Nod1, an Apaf-1-like activator of caspase-9 and nuclear factor-kappaB. J Biol Chem 1999; 274: 14560-14567.

41. Masumoto J, Taniguchi S, Ayukawa K, Sarvotham H, Kishino T, Niikawa N et al. ASC, a novel 22-kDa protein, aggregates during apoptosis of human promyelocytic leukemia HL-60 cells. J Biol Chem 1999; 274: 33835-33838.
42. Conway KE, McConnell BB, Bowring CE, Donald CD, Warren ST, Vertino PM. TMS1, a novel proapoptotic caspase recruitment domain protein, is a target of methylation-induced gene silencing in human breast cancers. Cancer Res 2000; 60: 6236-6242.

43. McConnell BB, Vertino PM. TMS1/ASC: the cancer connection. Apoptosis 2004; 9: 5-18.

44. Ohtsuka T, Ryu H, Minamishima YA, Macip S, Sagara J, Nakayama KI et al. ASC is a Bax adaptor and regulates the p53-Bax mitochondrial apoptosis pathway. Nat Cell Biol2004; 6 : $121-128$.

45. Motani K, Kushiyama H, Imamura R, Kinoshita T, Nishiuchi T, Suda T. Caspase-1 protein induces apoptosis-associated speck-like protein containing a caspase recruitment domain (ASC)-mediated necrosis independently of its catalytic activity. J Biol Chem 2011; 286: 33963-33972.

46. Kumar Y, Radha V, Swarup G. Interaction with Sug1 enables Ipaf ubiquitination leading to caspase 8 activation and cell death. Biochem J 2010; 427: 91-104.

47. Zhou Q, Snipas S, Orth K, Muzio M, Dixit VM, Salvesen GS. Target protease specificity of the viral serpin CrmA. Analysis of five caspases. J Biol Chem 1997; 272: 7797-7800.

48. Chen IF, Ou-Yang F, Hung JY, Liu JC, Wang H, Wang SC et al. AIM2 suppresses human breast cancer cell proliferation in vitro and mammary tumor growth in a mouse model. $\mathrm{Mol}$ Cancer Ther 2006; 5: 1-7.

49. Woerner SM, Kloor M, Schwitalle Y, Youmans H, Doeberitz M, Gebert J et al. The putative tumor suppressor AIM2 is frequently affected by different genetic alterations in microsatellite unstable colon cancers. Genes Chromosomes Cancer 2007; 46: 1080-1089.

50. Kuida K, Lippke JA, Ku G, Harding MW, Livingston DJ, Su MS et al. Altered cytokine export and apoptosis in mice deficient in interleukin-1 beta converting enzyme. Science 1995; 267: 2000-2003.

51. Mariathasan S, Newton K, Monack DM, Vucic D, French DM, Lee WP et al. Differentia activation of the inflammasome by caspase-1 adaptors ASC and Ipaf. Nature 2004; 430 213-218.

52. Wang S, Miura M, Jung YK, Zhu H, Li E, Yuan J. Murine caspase-11, an ICE-interacting protease, is essential for the activation of ICE. Cell 1998; 92: 501-509.

53. Martinon F, Petrilli V, Mayor A, Tardivel A, Tschopp J. Gout-associated uric acid crystals activate the NALP3 inflammasome. Nature 2006; 440: 237-241.

54. Ogilvy S, Metcalf D, Print CG, Bath ML, Harris AW, Adams JM. Constitutive Bcl-2 expression throughout the hematopoietic compartment affects multiple lineages and enhances progenitor cell survival. Proc Natl Acad Sci USA 1999; 96: 14943-14948.

55. O'Reilly LA, Ekert P, Harvey N, Marsden V, Cullen L, Vaux DL et al. Caspase-2 is not required for thymocyte or neuronal apoptosis even though cleavage of caspase-2 is dependent on both Apaf-1 and caspase-9. Cell Death Differ 2002; 9: 832-841.

56. Sester DP, Brion K, Trieu A, Goodridge HS, Roberts TL, Dunn J et al. CpG DNA activates survival in murine macrophages through TLR9 and the phosphatidylinositol 3-kinase-Akt pathway. J Immunol 2006; 177: 4473-4480.

57. Hornung V, Bauernfeind F, Halle A, Samstad EO, Kono H, Rock KL et al. Silica crystals and aluminum salts activate the NALP3 inflammasome through phagosomal destabilization. Nat Immunol 2008; 9: 847-856.

58. Stacey KJ, Young GR, Clark F, Sester DP, Roberts TL, Naik $S$ et al. The molecular basis for the lack of immunostimulatory activity of vertebrate DNA. J Immunol 2003; 170: 3614-3620.

59. Stacey KJ, Ross IL, Hume DA. Electroporation and DNA-dependent cell death in murine macrophages. Immunol Cell Biol 1993; 71(Pt 2): 75-85.

60. O'Reilly LA, Divisekera U, Newton K, Scalzo K, Kataoka T, Puthalakath $\mathrm{H}$ et al. Modifications and intracellular trafficking of FADD/MORT1 and caspase-8 after stimulation of T lymphocytes. Cell Death Differ 2004; 11: 724-736.

61. Masumoto J, Taniguchi S, Sagara J. Pyrin N-terminal homology domain- and caspase recruitment domain-dependent oligomerization of ASC. Biochem Biophys Res Commun 2001; 280: 652-655. 